\title{
Mechanism design of reverse auction on concession period and generalized quality for PPP projects
}

(C) The Author(s) 2017. Published by Higher Education Press. This is an open access article under the CC BY license (http:// creativecommons.org/licenses/by/4.0)

\begin{abstract}
Reverse auctions of PPP projects usually require the bid to specify several characteristics of quality and the concession period to be fulfilled. This paper sets up a summary function of generalized quality, which contributes to reducing the dimensions of information. Thus, the multidimensional reverse auction model of a PPP project can be replaced by a two-dimensional direct mechanism based on the concession period and the generalized quality. Based on the theory of the revelation principle, the feasibility conditions, equilibrium solution and generalized quality requirements of such a mechanism, considering the influence of a variable investment structure are described. Moreover, two feasible multidimensional reverse auctions for implementing such a direct mechanism: Adjusting the scoring function and establishing a special reverse auction rule are built. The analysis shows that in these types of reverse auctions, optimal allocation can be achieved, the social benefit under the incomplete information will be maximized, and the private sector with the highest integrated management level wins the bid. In such a direct mechanism, the investment and financial pressure of the public sector can be reduced.
\end{abstract}

Keywords PPP project, reverse auction, mechanism design, multidimensional information, scoring function, two-stage bidding

\section{Introduction}

Since the reform and opening up of the country to domestic investment, China has had an ever-growing demand for infrastructure, including electricity, transportation and

Received March 15, 2017; accepted May 10, 2017

Xianjia WANG, Shiwei WU ( $₫)$

School of Economic and Management, Wuhan University, Wuhan 430072, China

E-mail: shiweiwu@whu.edu.cn affordable housing. Studies have shown that infrastructure is the key input for vibrant and sustainable economic growth (Chukwuemeka et al., 2013). Currently, government investment is the major source of funding for China's infrastructure construction. However, with the intensification of conflicts on issues such as huge development capital, long payback periods, high project risks and low management and operational levels, new problems constantly arise with the financing, development and operation of infrastructure construction in China. To solve these problems, the State Council issued "Guidance on Encouraging Social Investment with Innovative Investment and Financing Mechanisms in Key Sectors" and proposed establishing a sound mechanism of PPP project mode in 2014. PPP project mode means the government establishes a long-term cooperative relationship with the private sector to share risks and benefits by means of franchises, purchases of services and equity cooperation to speed up infrastructure construction (Li, 2016). Currently, determining how to choose the private sector with the highest integrated management level as well as the optimal financing, development, construction and operational programs has become a key issue in the PPP project development process. The reverse auction, widely used in government procurement (Settoon and Wyld, 2003), municipal construction (Hanák, 2016) and city operation (Hua, 2014), is an effective choice mechanism for the public sector to select the private sector. Reverse auctions for PPP projects usually require the bid to specify both several characteristics of quality and the concession period to be fulfilled. However, how the public sector designs a feasible reverse auction mechanism for a PPP project with incomplete information is still a new field of research. Therefore, this paper studies the mechanism design and implementation of a multidimensional reverse auction for PPP projects. The purpose of this paper is to establish that through such reverse auctions the public sector can maximize its revenue, incentivize the private sectors' bid based on their true integrated management and reduce its 
financial pressure.

Domestic and foreign researchers have achieved some results in the studies of one-dimensional information reverse auction mechanism for traditional development model of infrastructure projects. Dequiedt (2007) has designed an optimal reverse auction mechanism by introducing a "virtual third party." Che and Kim (2009) have established a sub-optimal reverse auction model according to the revelation principle. Yin and Wang (2006), Huang and Chen (2010) have discussed the design issues of government procurement and reverse auction mechanism by adopting the design philosophy of incentive mechanism. Lengwiler and Wolfstetter (2010) and Zhou et al. (2011) have designed an incentive contract to offer certain profits to bidding agencies to prevent agent corruption. Wang et al. (2012) have designed a model of public service reverse auction mechanism based on the supply chain theory.

Considering the complexity of infrastructure construction projects, the public sector needs to consider both the bid price and other non-price information such as quality and the construction period to better achieve project objectives. A reverse auction mechanism with onedimensional information is not sufficient for tendering the requirements of large and complex projects. For studies of reverse auctions with multidimensional information, Bichler $(2000,2001)$ defined the multidimensional information reverse auction as a reverse auction mode for the bid inviter and bidder to make multiple negotiations on other attributes besides a single attribute. It has been proven that multi-attribute reverse auctions are more effective than single attribute reverse auctions. Based on price and quality, Che (1993), Yin and Wang (2008), Wang et al. (2010), Nishimura et al. (2015) established a twodimensional model of a reverse auction to improve the effectiveness of government tendering. With Che (1993)'s research as the basis, David et al. (2006), Zhao and Wang (2012), Nishimura (2015), et al. expanded the single nonprice variable into a series of variables. Wu et al. (2012) applied the revelation principle to establish a direct mechanism model for two-dimensional reverse auction contracts based on project cost and the franchise period.

As it is different from the bidding for traditional infrastructure projects, the public sector needs to consider the integrated management capabilities and the project proposal of the private sector during the PPP project bidding process. So, a PPP project reverse auction is based on multidimensional information such as a series of quality-related indexes, concerning construction and operation, and the concession period. However, current research on multidimensional information reverse auctions has mainly studied projects of a traditional development mode from the point of view of dimensions such as quality and price (Branco, 1997; Che, 1993; Wang et al., 2010) or franchise period and cost (Wu et al., 2012), which is difficult to reflect on PPP project tendering. In addition, the public and private sectors may make joint investments in PPP projects, but all current relevant research, such as Branco (1997) and Che (1993), have assumed that the projects are funded by one party, i.e., funded by the public sector or the private sector. The studies have ignored both diversified forms of cooperation of PPP projects and the impact of project investment structures on the tendering results. Therefore, determining how the model can better reflect PPP project bidding to help the public sector develop a reverse auction mechanism in a more scientific manner has become a new area of study. And how to comprehensively consider the impact of alterable investment structures in the model is also a new topic of study. In addition, multidimensional information has made the incentive situation of PPP projects more complex. Current research on multidimensional information reverse auction mechanisms reduces the dimensions of information mainly based on "black box" principles or relevant assumptions, which lacks practical significance. Therefore, how to scientifically reduce the number of dimensions of information and simplify the incentive situation has become a new area of research. Moreover, a superior mechanism design must have a Nash equilibrium that can be implemented. Current research on implementing such mechanism focuses on exchanging the scoring function in reverse auction. Therefore, the design of a different reverse auction to implement such mechanism is also a new area of research.

In summary, based on the theory of green management appraisal, this paper sets up the summary function of generalized quality, which contributes to reducing the dimensions of information. Introducing the variable of investment structure, and relying on the revelation principle (Myerson, 1979), this paper studies the twodimensional direct mechanism of the concession period and generalized quality. Through solution of the model, this paper describes the feasibility conditions, equilibrium solution and generalized quality requirements of such a mechanism. Moreover, this paper builds two feasible multidimensional reverse auctions based on adjusting the scoring function or establishing a special reverse auction rule, for implementing the mechanism. Finally, through numerical analysis of a practical example, this paper proves the scientific nature, feasibility and validity of this mechanism.

\section{The summary function of generalized quality}

There are many differences between PPP projects and traditional projects with regards to tendering: 1) PPP project tender documents list only the basic requirements, and bidders can make full use of their expertise and innovative ability; 2) certain contents of PPP project tender documents, such as the scope and technical requirements 
of the project, are negotiable depending on the situation; 3 ) in addition to the project construction program, the private sector also needs to prepare a project financing program, project design drawings and an operational program, etc. in the PPP project tendering process; 4) during the PPP project bid evaluation stage, the bid evaluator negotiates with bidders on aspects such as design, financing and operations, and the bidders are encouraged to propose new ideas in order to optimize the project; 5) PPP projects have flexible bid evaluation criteria, and a comprehensive evaluation of the project design, financing, construction and operational programs as well as the overall strength of the bidders is made. Due to these differences, PPP projects are different from conventional projects with regards to confirming the evaluation criterion.

The purpose of the generalized quality summary function is to integrate the quality-related program indexes in the PPP project reverse auction into a specific measurable indicator, i.e., to integrate and simplify the quality-related multidimensional information into onedimensional information. Two critical issues will be addressed for establishing a generalized quality summary function for infrastructure projects under the current PPP mode, i.e., indicator identification and the indicator integrating method.

Since the generalized quality function influences the reverse auction decisions of those inviting bids and those making bids, Table 1 summarizes the generalized quality indexes of a PPP project into six categories based on correlational research (Ke et al., 2010; Dong, 2013; Xu, 2014) and principles such as independence, completeness, constitutive property, conciseness, objective comparability and consistency.

Since the indexes of the generalized quality function have different dimensions, and since PPP project tendering is different from traditional project tendering, there is no absolute rule for judging each indicator of a PPP project. Therefore, by adopting the calculation methods of existing literature as a reference and combining the characteristics of PPP project tendering, this paper determines the ideal value of each indicator based on historical data and the ideal point method. The method transforms the indexes of different dimensions into the same dimension by calculating their Euclidean distance to facilitate calculations, and implements index weight by the analytic hierarchy process to integrate the indexes of different weights into generalized quality.

This paper supposes there are $N$ private sector participants in a PPP project reverse auction. The grade of the criterion layer index $j$ in private $i$ 's bidding scheme is denoted by $z_{i j}(j=1,2, \ldots, 6)$, and the value of sub-index $k$ under index $j$ is $z_{i j k}$, which is objective data in the bidding document or the scheme score determined by experts. Because the calculation method of sub-indexes is the same as that of the criterion layer index, this paper focuses on the calculation method for the criterion layer index.

Let each index $z_{i j}$ have the ideal value $o_{j}$, then all the deviations from the ideal value will contribute to the reduction of project quality, which decreases with the level of deviation. The ideal value can be determined from historical data or the highest index value of the bidding scheme. The Euclidean distance between index $z_{i j}$ and its ideal value $o_{j}$ can be calculated as $D_{i j}=\left(\frac{z_{i j}-o_{j}}{o_{j}}\right)^{2}$. The Euclidean score of $z_{i j}$ is $\tilde{D}_{i j}=1-\sqrt{\frac{D_{i j}}{\max _{i} D_{i j}}} \in[0,1]$, where poor quality is denoted by ' 0 ' and excellent quality is denoted by ' 1 '.

Using Eq. (1), the generalized quality $Q_{i}$ of private $i$ 's bidding scheme can be determined where the index weight is denoted by $\rho_{j}$. To eliminate cognitive differences of PPP project between experts, $\rho_{j}$ are determined by group evaluation and the use of an analytical hierarchy process.

$$
Q_{i}=\rho_{1} \tilde{D}_{i 1}+\rho_{2} \tilde{D}_{i 2}+\rho_{3} \tilde{D}_{i 3}+\rho_{4} \tilde{D}_{i 4}+\rho_{5} \tilde{D}_{i 5}+\rho_{6} \tilde{D}_{i 6} .
$$

Table 1 The generalized quality indicator system of PPP project

\begin{tabular}{|c|c|}
\hline Criterion layer $z_{i j}$ & Element layer $z_{i j k}$ \\
\hline Financing plan & Financing capacity; financing cost; fund using plan; financing options; financial regulatory; financing experience \\
\hline Project design & $\begin{array}{l}\text { Design conception; designing method; the technology and depth requirements of design; structure, layout, function; } \\
\text { feasibility }\end{array}$ \\
\hline $\begin{array}{l}\text { Forming planning of project } \\
\text { company }\end{array}$ & $\begin{array}{l}\text { Capital structure; organization establishment; experience; qualified technician; operating capability; dispatching of rights } \\
\text { and obligations }\end{array}$ \\
\hline Construction scheme & $\begin{array}{l}\text { Construction schedule; equipment; safety program; construction technique; invitation for bids; purchase plan; } \\
\text { construction cost; environmental controls; quality surveillance; control of investment }\end{array}$ \\
\hline Operation scheme & Scheme of test run; profitability; operation plan; maintenance measure; transfer plan \\
\hline Risk factor & $\begin{array}{c}\text { Economic risk; legal risk; political risk; environment risk; social risks; market risk; operational risk; construction risk; } \\
\text { cooperation risk; management risk }\end{array}$ \\
\hline
\end{tabular}




\section{The multidimensional direct mechanism of a PPP project reverse auction}

In the reverse auction of an infrastructure PPP project, the public sector always hopes to choose the participant in the private sector whose bidding document maximizes expected revenue, and who can complete the project. However, only considering generalized quality in the PPP project reverse auction may reduce the public sector's revenue, because the private sector can extend the project concession period to improve its profit. Therefore, the fulfillment of the PPP project requires choosing the concession period $T_{i}$ and generalized quality $Q_{i}$ which aggregates all the quality indexes related to the project. Therefore, the public sector should design the reverse auction mechanism of a PPP project based on the concession period and the generalized quality. The utilitarian public sector prefers to choose one from $N$ private sectors to carry out a single indivisible PPP project in cooperation with him. The private sector $i$ 's bid, $b_{i}=$ $\left(Q_{i}, T_{i}\right) \quad(1 \leqslant i \leqslant N)$, specifies a bidding document with generalized quality and a concession period. Prior to the reverse auction, each private sector $i$ privately knows its integrated management capacity parameter $\theta_{i}$, and the public sector knows only the distribution function of the integrated management capacity parameter. Therefore, the game of the reverse auction for the PPP project is equivalent to gambling with incomplete information. According to Myerson (1979)'s research, the goal of the public sector can be identified as a direct revelation mechanism in which there is a Bayesian Nash equilibrium for all private sectors to reveal their true integrated management capacity parameters. Therefore, based on mechanism design theory and incentive compatible mechanisms, this paper explores how the public sector designs a reverse auction mechanism for a PPP project, eliminating the impact of asymmetric information.

\subsection{Modeling of multidimensional direct mechanisms}

The public sector wants to choose one from $N$ private sectors to cooperatively carry out a single indivisible PPP project. Private sector $i$ holds its integrated management capacity parameter $\theta_{i}$ as private information, where the capacity increases with $\theta_{i}$. All participants know only the distribution function of $\theta_{i}$, which is independently and identically distributed over $[\underline{\theta}, \bar{\theta}](\underline{\theta}<\bar{\theta})$, based on a distribution function $F(\cdot)$ where there exists a nonnegative, continuously differentiable density function $f(\cdot)$. The density has a non-decreasing hazard rate as shown in Eq. (2).

$$
\frac{\partial\left[\frac{1-F\left(\theta_{i}\right)}{f\left(\theta_{i}\right)}\right]}{\partial \theta_{i}}<0 .
$$

Each bid, $b_{i}$ specifies a bidding document with a generalized quality and concession period. The generalized quality $Q_{i}\left(\theta_{i}\right)$, which is observed in the private sector $i$ 's bidding document only depends on the its integrated management capacity $\theta_{i}$, and an uncorrelated variable. The generalized quality $Q_{i}\left(\theta_{i}\right)$ cannot be lower than the minimum quality $Q_{0}$ defined in the tender documents of the PPP project, that is $Q_{i}\left(\theta_{i}\right) \geqslant Q_{0}$. The concession period $T_{i}\left(\theta_{i}\right)$ bidded by the private sector $i$ satisfies a singlecrossing condition. The income from carrying out the PPP project in the concession period $T_{i}\left(\theta_{i}\right)$ is given by the earnings function $\mu\left(T_{i}\left(\theta_{i}\right)\right)$. If private sector $i$ carries out the project with $Q_{i}\left(\theta_{i}\right)$, its cost will be $C\left(Q_{i}\left(\theta_{i}\right), \theta_{i}, \xi\left(\theta_{-i}\right)\right)$. This depends not only on its integrated management capacity $\theta_{i}$ (an idiosyncratic component) but also on its social efficiency and technology (a common component). This paper defines $\xi\left(\theta_{-i}\right)$ as the social efficiency and technology related to $\theta_{-i}$ which is the vector of all private sectors' capacity except for that of $i, \theta_{-i}=\left(\theta_{1}, \ldots, \theta_{i-1}\right.$, $\left.\theta_{i+1}, \ldots, \theta_{n}\right)$. If $\xi\left(\theta_{-i}\right)$ is constant, $C\left(Q_{i}\left(\theta_{i}\right), \theta_{i}, \xi\left(\theta_{-i}\right)\right)$ will be an independent variable. $\lambda\left(Q_{i}\left(\theta_{i}\right)\right)$ is private sector $i$ 's investment weight of the PPP project with quality $Q_{i}\left(\theta_{i}\right)$; therefore, the public sector's is $1-\lambda\left(Q_{i}\left(\theta_{i}\right)\right), \lambda\left(Q_{i}\left(\theta_{i}\right)\right)$ $\in[0,1]$, where $\lambda(\cdot)$ is the weight function which is described in the tender document. The entire value of fulfilling the PPP project with quality $Q_{i}\left(\theta_{i}\right)$ is given by the function $w\left(Q_{i}\left(\theta_{i}\right)\right)$. In addition, there is a welfare cost of raising public funds, $c_{v}$.

According to the mechanism design theory, the tenderees of the PPP project may design a set of selection and payment rule, $(P(\theta), Z(b)) . P(\theta)=\left\{P_{i}\left(\theta_{i}, \theta_{-i}\right)\right\}, i=$ $1,2, \ldots, N$ is the selection rule, in which $P_{i}\left(\theta_{i}, \theta_{-i}\right)$ is described as the probability that private sector $i$ is selected under the condition that all the private sectors except $i$ finish the tender documents based on their real capacity. The functions $P_{i}\left(\theta_{i}, \theta_{-i}\right)$ satisfy $0 \leqslant P_{i} \leqslant 1$ and $\sum_{i=1}^{N} P_{i} \leqslant 1$. Let $Z(b)=\left\{Z\left(b_{i}\right)\right\},(i=1,2, \ldots, N), Z\left(b_{-i}\right)=0$, then $Z\left(b_{i}\right)=\mu\left(T_{i}\left(\theta_{i}\right)\right)+\left(1-\lambda\left(Q_{i}\left(\theta_{i}\right)\right)\right) C\left(Q_{i}\left(\theta_{i}\right), \theta_{i}, \xi\left(\theta_{-i}\right)\right)$ is the payment rule. Private sector $i$ receives the virtual payment $Z\left(b_{i}\right)$ from the public sector in accordance with the bidding documents if $i$ wins the reverse auction and fulfills the contract. To summarize, the mechanisms can be described by the triad $\left(p_{i}\left(\theta_{i}, \theta_{-i}\right), Q_{i}\left(\theta_{i}\right), T_{i}\left(\theta_{i}\right)\right)$.

This paper assumes that both the public and private sectors are risk neutral and 'rational-economic entities' who maximize their own revenue. Therefore, the expected revenue of private sector $i$ generated by carrying out the PPP project is $U_{i}\left(\theta_{i}\right)$, Eq. (3). In Eq. (3), the $E_{\theta_{-i}}$ is the expectation operator which operates on the $(N-1)$ dimensional function space (Nishimura, 2015).

$$
\begin{aligned}
U_{i}\left(\theta_{i}\right) & =U\left(b_{i}\left(\theta_{i}\right), \theta_{i}\right) \\
& =E_{\theta_{-i}}\left[Z\left(b_{i}\left(\theta_{i}\right)\right)-C\left(Q_{i}\left(\theta_{i}\right), \theta_{i}, \xi\left(\theta_{-i}\right)\right)\right] P_{i}\left(\theta_{i}, \theta_{-i}\right)
\end{aligned}
$$




$$
\begin{aligned}
= & E_{\theta_{-i}}\left[\mu\left(T_{i}\left(\theta_{i}\right)\right)-\lambda\left(Q_{i}\left(\theta_{i}\right)\right) C\left(Q_{i}\left(\theta_{i}\right), \theta_{i}, \xi\left(\theta_{-i}\right)\right)\right] \\
& \cdot P_{i}\left(\theta_{i}, \theta_{-i}\right) .
\end{aligned}
$$

Because of the rational hypothesis, the private sector is willing to attend the reverse auction if and only if their expected revenue is larger than the risk-free return, Eq. (4), which is the participation constraint.

$$
U\left(b_{i}\left(\theta_{i}\right), \theta_{i}\right) \geqslant U_{0} .
$$

The public sector's expected revenue generated in cooperation with $i$ is $W\left(Q_{i}\left(\theta_{i}\right), T_{i}\left(\theta_{i}\right)\right)$ Eq. (5).

$$
\begin{aligned}
W= & W\left(Q_{i}\left(\theta_{i}\right), T_{i}\left(\theta_{i}\right)\right) \\
= & E_{\theta}\left[w\left(Q_{i}\left(\theta_{i}\right)\right)-Z\left(b_{i}\left(\theta_{i}\right)\right)\right] P_{i}\left(\theta_{i}, \theta_{-i}\right) \\
= & E_{\theta}\left[w\left(Q_{i}\left(\theta_{i}\right)\right)-\left(1+c_{v}\right)\left(1-\lambda\left(Q_{i}\left(\theta_{i}\right)\right)\right)\right. \\
& \left.\cdot C\left(Q_{i}\left(\theta_{i}\right), \theta_{i}, \xi\left(\theta_{-i}\right)\right)-\mu\left(T_{i}\left(\theta_{i}\right)\right)\right] P_{i}\left(\theta_{i}, \theta_{-i}\right) .
\end{aligned}
$$

On account of information asymmetry, private sector $i$ may mimic other integrated management capacity $\tilde{\theta}_{i} \in[\underline{\theta}, \bar{\theta}] \neq \theta_{i}$, to win the contract for the PPP project. Let $V\left(\tilde{\theta}_{i}, \theta_{i}\right),\left(\tilde{\theta}_{i}, \theta_{i}\right) \in(\underline{\theta}, \bar{\theta}) \times(\underline{\theta}, \bar{\theta})$ be private sector $i$ 's expected revenue if he mimics capacity $\tilde{\theta}_{i}$, when all the other private sector participants truthfully reveal their capacity. Then,

$$
\begin{aligned}
V\left(\tilde{\theta}_{i}, \theta\right)= & E_{\theta_{-i}}\left[\mu\left(T_{i}\left(\tilde{\theta}_{i}\right)\right)-\lambda\left(Q_{i}\left(\tilde{\theta}_{i}\right)\right) C\left(Q_{i}\left(\tilde{\theta}_{i}\right),\right.\right. \\
& \left.\left.\theta_{i}, \xi\left(\theta_{-i}\right)\right)\right] P_{i}\left(\tilde{\theta}_{i}, \theta_{-i}\right) .
\end{aligned}
$$

By the revelation principle, the public sector could induce the private sector to disclose their true capacity. Therefore, the public sector needs to ensure that the expected revenue $i$ receives by 'telling the truth', is higher than what he receives by deception.

$$
U_{i}\left(\theta_{i}\right)=U\left(b_{i}\left(\theta_{i}\right), \theta_{i}\right)=\max V\left(\tilde{\theta}_{i}, \theta_{i}\right)=V\left(\theta_{i}, \theta_{i}\right) .
$$

In conclusion, the public sector designs the direct mechanism of a PPP project, which is transformed into solving an optimization problem (Wu et al., 2012). This consists of solving the objective function Eq. (5) maximization problem under the constraints of participation Eq. (4) and incentive compatibility Eq. (7). The objective function of the optimization problem $\left(p_{i}\left(\theta_{i}, \theta_{-i}\right)\right.$, $\left.Q_{i}\left(\theta_{i}\right), T_{i}\left(\theta_{i}\right)\right)$ is to maximize the public sector's profit.

\subsection{Assumptions of multidimensional direct mechanism}

For the sake of analysis, this paper makes the following assumptions based on the characteristics of PPP project operation and pertinent literature (Che,1993; Branco 1997; Wu et al., 2012; Wang et al., 2010).
Assumption 1: The cost function $C\left(Q_{i}\left(\theta_{i}\right), \theta_{i}, \xi\left(\theta_{-i}\right)\right)$ is increasing and convex in $Q_{i}$. Moreover, $C\left(0, \theta_{i}, \xi\left(\theta_{-i}\right)\right)$ $=0$. Then

$$
C_{Q_{i}}=\frac{\partial C\left(Q_{i}, \theta_{i}, \xi\right)}{\partial Q_{i}}>0, C_{Q_{i} Q_{i}}=\frac{\partial^{2} C\left(Q_{i}, \theta_{i}, \xi\right)}{\partial Q_{i}^{2}}>0 .
$$

Assumption 2: The cost function $C\left(Q_{i}\left(\theta_{i}\right), \theta_{i}, \xi\left(\theta_{-i}\right)\right)$ is decreasing and convex in $\theta_{i}$. The marginal cost of quality is decreasing and convex in $\theta_{i}$, which ensures that $C\left(Q_{i}, \theta_{i}, \xi\right)$ satisfies the single-crossing property (Wu et al., 2012; Myerson, 1979):

$$
\begin{aligned}
& C_{\theta_{i}}=\frac{\partial C\left(Q_{i}, \theta_{i}, \xi\right)}{\partial \theta_{i}}<0, \\
& C_{\theta_{i} \theta_{i}}=\frac{\partial^{2} C\left(Q_{i}, \theta_{i}, \xi\right)}{\partial \theta_{i}^{2}}>0, \\
& C_{Q_{i} \theta_{i}}=\frac{\partial^{2} C\left(Q_{i}, \theta_{i}, \xi\right)}{\partial Q_{i} \partial \theta_{i}}<0, \\
& C_{\theta_{i} \theta_{i} Q_{i}}=\frac{\partial^{3} C\left(Q_{i}, \theta_{i}, \xi\right)}{\partial^{2} \theta_{i} \partial Q_{i}}>0 .
\end{aligned}
$$

Moreover, the cost function $C\left(Q_{i}\left(\theta_{i}\right), \theta_{i}, \xi\left(\theta_{-i}\right)\right)$ needs to meet the following conditions:

$$
C_{\theta_{i} Q_{i} Q_{i}}=\frac{\partial^{3} C\left(Q_{i}, \theta_{i}, \xi\right)}{\partial^{2} Q_{i} \partial \theta_{i}}<0, \frac{\partial}{\partial \theta_{i}} \frac{\frac{\partial^{2} C\left(Q_{i}, \theta_{i}, \xi\right)}{\partial Q_{i}^{2}}}{\frac{\partial C\left(Q_{i}, \theta_{i}, \xi\right)}{\partial Q_{i}}}<0 .
$$

Assumption 3: The value of fulfilling the PPP project $w\left(Q_{i}\left(\theta_{i}\right)\right)$ is increasing and concave in $Q_{i}$.

$$
W_{Q_{i}}=\frac{\mathrm{d} W\left(Q_{i}\right)}{\mathrm{d} Q_{i}}>0, W_{Q_{i} Q_{i}}=\frac{\mathrm{d}^{2} W\left(Q_{i}\right)}{\mathrm{d} Q_{i}^{2}}<0 .
$$

Assumption 4: The income function $\mu\left(T_{i}\left(\theta_{i}\right)\right)$ is increasing and concave in $T_{i}$ :

$$
\mu_{T}=\frac{\mathrm{d} \mu\left(T_{i}\right)}{\mathrm{d} T_{i}}>0, \mu_{T T}=\frac{\mathrm{d}^{2} \mu\left(T_{i}\right)}{\mathrm{d} T_{i}^{2}}<0 .
$$

Assumption 5: The investment proportion function of the private sector $\lambda\left(Q_{i}\left(\theta_{i}\right)\right)$ is increasing and concave in $Q_{i}$ :

$$
\lambda_{Q_{i}}=\frac{\mathrm{d} \lambda\left(Q_{i}\right)}{\mathrm{d} Q_{i}}>0, \lambda_{Q_{i} Q_{i}}=\frac{\mathrm{d}^{2} \lambda\left(Q_{i}\right)}{\mathrm{d} Q_{i}^{2}}<0 .
$$

Moreover, the investment proportion function $\lambda\left(Q_{i}\left(\theta_{i}\right)\right)$ satisfies the following condition:

$$
\frac{\lambda_{\theta_{i}}}{\lambda\left(Q_{0}\right)} \leqslant-\frac{C_{\theta_{i} \theta_{i}}}{C_{\theta_{i}}},-\frac{W_{Q_{i} Q_{i}}}{c_{v} C_{Q_{i}}} \leqslant \lambda_{Q_{i}} \leqslant \frac{C_{Q_{i} Q_{i}}}{c_{v} C_{Q_{i}}} .
$$

The reason for Assumption 5 is that the public sector seeks to encourage the private sector to improve the quality of PPP projects; therefore, it is willing to supply funds for a 
high-quality project. However, given limited financial resources, the growth rate of fiscal appropriations is lower than that of cost.

Assumption 6: Let $\theta_{j} \in\left\{\theta_{-i}\right\}$, the component of social efficiency and technology $\xi\left(\theta_{-i}\right)$ increase with $\theta_{j}$.

$$
\frac{\partial \xi\left(\theta_{-i}\right)}{\partial \theta_{j}}>0
$$

3.3 Feasibility conditions of a direct mechanism for a PPP project reverse auction

Before discussing the optimal mechanism of a PPP project reverse auction, the feasibility conditions for the direct mechanism need to be studied. If private sectors never falsify information, the feasibility condition for incentive compatibility is as follow:

$$
\left.\frac{\partial V\left(\tilde{\theta}_{i}, \theta_{i}\right)}{\partial \tilde{\theta}_{i}}\right|_{\tilde{\theta}_{i}=\theta_{i}}=0 .
$$

The following essential relationship can then be determined:

$$
\begin{aligned}
& {\left[\frac { \mathrm { d } \lambda ( Q _ { i } ( \theta _ { i } ) ) } { \mathrm { d } Q _ { i } } C \left(Q_{i}\left(\theta_{i}\right), \theta_{i}, \xi\left(\theta_{-i}\right)+\lambda\left(Q_{i}\left(\theta_{i}\right)\right)\right.\right.} \\
& \left.\cdot \frac{\partial C\left(Q_{i}\left(\theta_{i}\right), \theta_{i}, \xi\left(\theta_{-i}\right)\right)}{\partial Q_{i}}\right] \frac{\mathrm{d} Q_{i}\left(\theta_{i}\right)}{\mathrm{d} \theta_{i}} \\
& =\frac{\mathrm{d} \mu\left(T_{i}\left(\theta_{i}\right)\right)}{\mathrm{d} T_{i}} \frac{\mathrm{d} T_{i}\left(\theta_{i}\right)}{\mathrm{d} \theta_{i}} .
\end{aligned}
$$

From the feasibility condition for incentive compatibility Eq. (17), the following lemma is satisfied:

Lemma 1: The generalized quality $Q_{i}\left(\theta_{i}\right)$ is increasing with $i$ 's capacity $\theta_{i}$.

$$
\frac{\mathrm{d} Q_{i}\left(\theta_{i}\right)}{\mathrm{d} \theta_{i}}>0
$$

Proof:

The inequality Eq. (18) is proved as follow. The derivative of $V\left(\tilde{\theta}_{i}, \theta_{i}\right)$ with respect to $\tilde{\theta}_{i}$ is:

$$
\begin{aligned}
\frac{\partial V\left(\tilde{\theta}_{i}, \theta_{i}\right)}{\partial \tilde{\theta}_{i}}= & \left\{\frac{\mathrm{d} \mu\left(T_{i}\left(\tilde{\theta}_{i}\right)\right)}{\mathrm{d} T_{i}} \frac{\mathrm{d} T_{i}\left(\tilde{\theta}_{i}\right)}{\mathrm{d} \tilde{\theta}_{i}}\right. \\
& -\left[\frac { \mathrm { d } \lambda Q _ { i } ( \tilde { \theta } _ { i } ) } { \mathrm { d } Q _ { i } } C \left(Q_{i}\left(\tilde{\theta}_{i}\right), \theta_{i}, \xi\left(\theta_{-i}\right)\right.\right. \\
& \left.+\lambda\left(Q_{i}\left(\tilde{\theta}_{i}\right) \frac{\partial C\left(Q_{i}\left(\tilde{\theta}_{i}\right), \theta_{i}, \xi\left(\theta_{-i}\right)\right)}{\partial Q_{i}}\right] \frac{\mathrm{d} Q_{i}\left(\tilde{\theta}_{i}\right)}{\mathrm{d} \tilde{\theta}_{i}}\right\} p_{i} .
\end{aligned}
$$

Substituting Eq. (17) into (19) to rewrite $\frac{\partial V\left(\tilde{\theta}_{i}, \theta_{i}\right)}{\partial \tilde{\theta}_{i}}$,

$$
\begin{aligned}
\frac{\partial V\left(\tilde{\theta}_{i}, \theta_{i}\right)}{\partial \tilde{\theta}_{i}}= & \left\{\frac { \mathrm { d } \lambda ( Q _ { i } ( \tilde { \theta } _ { i } ) ) } { \mathrm { d } Q _ { i } } \left[C \left(Q_{i}\left(\tilde{\theta}_{i}\right), \tilde{\theta}_{i}, \xi\left(\theta_{-i}\right)\right.\right.\right. \\
& -C\left(Q_{i}\left(\tilde{\theta}_{i}\right), \theta_{i}, \xi\left(\theta_{-i}\right)\right]+\lambda\left(Q_{i}\left(\tilde{\theta}_{i}\right)\right)
\end{aligned}
$$

$$
\begin{aligned}
& \cdot\left[\frac{\partial C\left(Q_{i}\left(\tilde{\theta}_{i}\right), \tilde{\theta}_{i}, \xi\left(\theta_{-i}\right)\right)}{\partial Q_{i}}\right. \\
& \left.\left.-\frac{\partial C\left(Q_{i}\left(\tilde{\theta}_{i}\right), \theta_{i}, \xi\left(\theta_{-i}\right)\right)}{\partial Q_{i}}\right]\right\} \frac{\mathrm{d} Q_{i}\left(\tilde{\theta}_{i}\right)}{\mathrm{d} \tilde{\theta}_{i}} p_{i} .
\end{aligned}
$$

From Assumption 2, Assumption 5 and Eq. (16) the following inequalities are obtained. When $\tilde{\theta}_{i}<\theta_{i}$,

$$
\frac{\partial V\left(\tilde{\theta}_{i}, \theta_{i}\right)}{\partial \tilde{\theta}_{i}}>0
$$

$$
\begin{aligned}
& \frac{\mathrm{d} \lambda\left(Q_{i}\left(\tilde{\theta}_{i}\right)\right)}{\mathrm{d} Q_{i}}\left[C\left(Q_{i}\left(\tilde{\theta}_{i}\right), \tilde{\theta}_{i}, \xi\left(\theta_{-i}\right)\right)-C\left(Q_{i}\left(\tilde{\theta}_{i}\right), \theta_{i}, \xi\left(\theta_{-i}\right)\right)\right]>0, \\
& \lambda\left(Q_{i}\left(\tilde{\theta}_{i}\right)\right)\left[\frac{\partial C\left(Q_{i}\left(\tilde{\theta}_{i}\right), \tilde{\theta}_{i}, \xi\left(\theta_{-i}\right)\right)}{\partial Q_{i}}-\frac{\partial C\left(Q_{i}\left(\tilde{\theta}_{i}\right), \theta_{i}, \xi\left(\theta_{-i}\right)\right)}{\partial Q_{i}}\right] \\
& \quad>0
\end{aligned}
$$

and when $\tilde{\theta}_{i}>\theta_{i}$,

$$
\frac{\partial V\left(\tilde{\theta}_{i}, \theta_{i}\right)}{\partial \tilde{\theta}_{i}}<0
$$

$\frac{\mathrm{d} \lambda\left(Q_{i}\left(\tilde{\theta}_{i}\right)\right)}{\mathrm{d} Q_{i}}\left[C\left(Q_{i}\left(\tilde{\theta}_{i}\right), \tilde{\theta}_{i}, \xi\left(\theta_{-i}\right)\right)-C\left(Q_{i}\left(\tilde{\theta}_{i}\right), \theta_{i}, \xi\left(\theta_{-i}\right)\right)\right]<0$,

$\lambda\left(Q_{i}\left(\tilde{\theta}_{i}\right)\right)\left[\frac{\partial C\left(Q_{i}\left(\tilde{\theta}_{i}\right), \tilde{\theta}_{i}, \xi\left(\theta_{-i}\right)\right)}{\partial Q_{i}}-\frac{\partial C\left(Q_{i}\left(\tilde{\theta}_{i}\right), \theta_{i}, \xi\left(\theta_{-i}\right)\right)}{\partial Q_{i}}\right]<0$.

From the previous inequalities, we conclude that the generalized quality $Q_{i}\left(\theta_{i}\right)$ is increasing in $\theta_{i}, \frac{\mathrm{d} Q_{i}\left(\theta_{i}\right)}{\mathrm{d} \theta_{i}}>0$.

From $Q_{i}\left(\theta_{i}\right) \geqslant Q_{0}$ and Eq. (18), the following inequality Eq. (21) can be determined:

$$
Q_{i}(\underline{\theta}) \geqslant Q_{0} .
$$

From Eqs. (17) and (18), and Assumptions 1, 3 and 5, Eq. (22) is found: 


$$
\frac{\mathrm{d} T_{i}\left(\theta_{i}\right)}{\mathrm{d} \theta_{i}}>0 .
$$

From Eqs. (16) and (17), and the envelope theorem (Branco, 1996) we have:

$$
\frac{\mathrm{d} U_{i}\left(\theta_{i}\right)}{\mathrm{d} \theta_{i}}=-E_{\theta_{-i}} \lambda\left(Q_{i}\left(\theta_{i}\right)\right) C_{\theta_{i}}\left(Q_{i}\left(\theta_{i}\right), \theta_{i}, \xi\left(\theta_{-i}\right)\right) p_{i}\left(\theta_{i}, \theta_{-i}\right) .
$$

Because of Assumption 2 and Eq. (23), the first-order derivative $\frac{\mathrm{d} U_{i}\left(\theta_{i}\right)}{\mathrm{d} \theta_{i}}$ is positive, and the following condition is satisfied.

$$
U_{i}(\underline{\theta}) \geqslant U_{0} .
$$

To facilitate the calculations, this paper postulates $U_{i}(\underline{\theta})=U_{0}=0$, which means that the expected revenue of the private sector with the lowest capacity is equivalent to risk-free return.

Proposition 1: If and only if the conditions Eqs. (17), (18), (21), (22) and (24), are satisfied, the direct mechanism of the PPP project reverse auction is feasible.

From Proposition 1, the private sector with superior abilities in integrated management stands out with respect to technology, project design, operation and cost controls. Under the same conditions, the generalized quality of the bidding documents submitted by the private sector with better integrated management is higher than that submitted by those in the private sector with poorly integrated management. Therefore, the generalized quality of a proposed scheme based on the feasible direct mechanism of PPP project bidding is an increasing function of the actual ability of the private sector with regards to integrated management. According to Assumption 1, improvements in project quality will lead to increases in the cost of project construction, operation and management. As a consequence, to ensure a certain profit, the better the abilities of the private sector in integrated management, and the longer the concession period will be. That is, the duration of franchise rights for proposed projects is also an increasing function of the actual abilities of the private sector in integrated management.

3.4 The optimal direct mechanism of PPP project reverse auction

Section 2 describes the feasibility conditions for the direct mechanism of a PPP project reverse auction. In this section, the optimal direct mechanism is derived under the feasibility conditions. The description of the optimal direct mechanism of a PPP project reverse auction may be summarized by the following proposition.

Proposition 2: In the optimal direct mechanism of a PPP project reverse auction, the private sector with the highest capacity wins the bid. The optimal allocation is

$$
\begin{aligned}
& \left(p_{i}^{*}\left(\theta_{i}, \theta_{-i}\right), Q_{i}^{*}\left(\theta_{i}\right), T_{i}^{*}\left(\theta_{i}\right)\right) \text { which is } \\
& \begin{array}{c}
Q_{i}^{*}\left(\theta_{i}\right)=\operatorname{argmax}\left[w\left(Q_{i}\left(\theta_{i}\right)\right)-C\left(Q_{i}\left(\theta_{i}\right), \theta_{i}, \xi\left(\theta_{-i}\right)\right)\right. \\
-c_{v}\left(1-\lambda\left(Q_{i}\left(\theta_{i}\right)\right)\right) C\left(Q_{i}\left(\theta_{i}\right), \theta_{i}, \xi\left(\theta_{-i}\right)\right) \\
\left.+\frac{1-F\left(\theta_{i}\right)}{f\left(\theta_{i}\right)} \lambda\left(Q_{i}\left(\theta_{i}\right)\right) C_{\theta_{i}}\left(Q_{i}\left(\theta_{i}\right), \theta_{i}, \xi\left(\theta_{-i}\right)\right)\right], \\
T_{i}^{*}\left(\theta_{i}\right)=u^{*^{-1}}\left(T_{i}^{*}\left(\theta_{i}\right)\right),
\end{array}
\end{aligned}
$$

where

$$
\begin{gathered}
u^{*}\left(T^{*}\left(\theta_{i}\right)\right)=\frac{E_{\theta_{-i}}}{F^{N-1}\left(\theta_{i}\right)}\left[\lambda\left(Q_{i}^{*}\left(\theta_{i}\right)\right) C\left(Q_{i}^{*}\left(\theta_{i}\right), \theta_{i}, \xi\left(\theta_{-i}\right)\right)\right. \\
\left.-\int_{\underline{\theta}}^{\theta_{i}} \lambda\left(Q_{i}^{*}(x)\right) C_{\theta_{i}}\left(Q_{i}^{*}(x), x, \xi\left(\theta_{-i}\right)\right) \mathrm{d} x\right], \\
p_{i}^{*}\left(\theta_{i}, \theta_{-i}\right)=\left\{\begin{array}{ll}
1 & \theta_{i}=\max \left\{\theta_{j}\right\}, \forall j \in N \\
0 & \theta_{i} \neq \max \left\{\theta_{j}\right\}, \forall j \in N
\end{array} .\right.
\end{gathered}
$$

Proof:

The public sector's expected revenue in the optimal direct mechanism can be written as

$$
\begin{aligned}
W= & E_{\theta}\left[w\left(Q_{i}\left(\theta_{i}\right)\right)-\left(1+c_{v}\right)\left(1-\lambda\left(Q_{i}\left(\theta_{i}\right)\right)\right)\right. \\
& \left.\cdot C\left(Q_{i}\left(\theta_{i}\right), \theta_{i}, \xi\left(\theta_{-i}\right)\right)-\mu\left(T_{i}\left(\theta_{i}\right)\right)\right] p_{i}\left(\theta_{i}, \theta_{-i}\right) \\
= & E_{\theta_{-i}} \sum_{i=1}^{N} \int_{\underline{\theta}}^{\bar{\theta}}\left[w\left(Q_{i}\left(\theta_{i}\right)\right)-\left(1+c_{v}\right)\left(1-\lambda\left(Q_{i}\left(\theta_{i}\right)\right)\right)\right. \\
& \left.\cdot C\left(Q_{i}\left(\theta_{i}\right), \theta_{i}, \xi\left(\theta_{-i}\right)\right)-\mu\left(T_{i}\left(\theta_{i}\right)\right)\right] p_{i}\left(\theta_{i}, \theta_{-i}\right) f\left(\theta_{i}\right) \mathrm{d} \theta_{i} \\
= & E_{\theta_{-i}} \sum_{i=1}^{N} \int_{\underline{\theta}}^{\bar{\theta}}\left[w\left(Q_{i}\left(\theta_{i}\right)\right)-\left(1+c_{v}\right) C\left(Q_{i}\left(\theta_{i}\right), \theta_{i}, \xi\left(\theta_{-i}\right)\right)\right. \\
& \left.+c_{v} \lambda\left(Q_{i}\left(\theta_{i}\right)\right) C\left(Q_{i}\left(\theta_{i}\right), \theta_{i}, \xi\left(\theta_{-i}\right)\right)\right] p_{i}\left(\theta_{i}, \theta_{-i}\right) f\left(\theta_{i}\right) \mathrm{d} \theta_{i} \\
& -\sum_{i=1}^{N} \int_{\underline{\theta}}^{\bar{\theta}} U_{i}\left(\theta_{i}\right) f\left(\theta_{i}\right) \mathrm{d} \theta_{i} \\
= & E_{\theta_{-i}} \sum_{i=1}^{N} \int_{\underline{\theta}}^{\bar{\theta}}\left[w\left(Q_{i}\left(\theta_{i}\right)\right)-\left(1+c_{v}\right) C\left(Q_{i}\left(\theta_{i}\right), \theta_{i}, \xi\left(\theta_{-i}\right)\right)\right. \\
& \left.+c_{v} \lambda\left(Q_{i}\left(\theta_{i}\right)\right) C\left(Q_{i}\left(\theta_{i}\right), \theta_{i}, \xi\left(\theta_{-i}\right)\right)\right] p_{i}\left(\theta_{i}, \theta \theta_{-i}\right) f\left(\theta_{i}\right) \mathrm{d} \theta_{i} \\
& +\left.\sum_{i=1}^{N}\left(1-F\left(\theta_{i}\right)\right) U_{i}\left(\theta_{i}\right)\right|_{\underline{\theta}} ^{\bar{\theta}}-\sum_{i=1}^{N} \int_{\underline{\theta}}^{\bar{\theta}}\left(1-F\left(\theta_{i}\right)\right) \frac{\mathrm{d} U_{i}\left(\theta_{i}\right)}{\mathrm{d} \theta_{i}} \mathrm{~d} \theta_{i}
\end{aligned}
$$




$$
\begin{aligned}
= & E_{\theta_{-i}} \sum_{i=1}^{N} \int_{\underline{\theta}}^{\bar{\theta}}\left[w\left(Q_{i}\left(\theta_{i}\right)\right)-\left(1+c_{v}\right) C\left(Q_{i}\left(\theta_{i}\right), \theta_{i}, \xi\left(\theta_{-i}\right)\right)\right. \\
& \left.+c_{v} \lambda\left(Q_{i}\left(\theta_{i}\right)\right) C\left(Q_{i}\left(\theta_{i}\right), \theta_{i}, \xi\left(\theta_{-i}\right)\right)\right] p_{i}\left(\theta_{i}, \theta_{-i}\right) f\left(\theta_{i}\right) \mathrm{d} \theta_{i} \\
& +\sum_{i=1}^{N}\left[U_{i}(\underline{\theta})+E_{\theta_{-i}} \int_{\underline{\theta}}^{\bar{\theta}}\left(1-F\left(\theta_{i}\right)\right) \lambda\left(Q_{i}\left(\theta_{i}\right)\right.\right. \\
& \left.\cdot C_{\theta_{i}}\left(Q_{i}\left(\theta_{i}\right), \theta_{i}, \xi\left(\theta_{-i}\right)\right) p_{i}\left(\theta_{i}, \theta_{-i}\right) \mathrm{d} \theta_{i}\right] \\
= & E_{\theta_{-i}} \sum_{i=1}^{N} \int_{\underline{\theta}}^{\bar{\theta}}\left[w\left(Q_{i}\left(\theta_{i}\right)\right)-C\left(Q_{i}\left(\theta_{i}\right), \theta_{i}, \xi\left(\theta_{-i}\right)\right)\right. \\
& -c_{v}\left(1-\lambda\left(Q_{i}\left(\theta_{i}\right)\right)\right) C\left(Q_{i}\left(\theta_{i}\right), \theta_{i}, \xi\left(\theta_{-i}\right)\right) \\
& \left.+\frac{1-F\left(\theta_{i}\right)}{f\left(\theta_{i}\right)} \lambda\left(Q_{i}\left(\theta_{i}\right)\right) C_{\theta_{i}}\left(Q_{i}\left(\theta_{i}\right), \theta_{i}, \xi\left(\theta_{-i}\right)\right)\right] \\
& \cdot p_{i}\left(\theta_{i}, \theta \theta_{-i}\right) f\left(\theta_{i}\right) \mathrm{d} \theta_{i} \\
= & \sum_{i=1}^{N} \int_{\underline{\theta}}^{\bar{\theta}} \ldots \int_{\underline{\theta}}^{\bar{\theta}}\left[w\left(Q_{i}\left(\theta_{i}\right)\right)-C\left(Q_{i}\left(\theta_{i}\right), \theta_{i}, \xi\left(\theta_{-i}\right)\right)\right. \\
& \left(1-\lambda\left(Q_{i}\left(\theta_{i}\right)\right)\right) C\left(Q_{i}\left(\theta_{i}\right), \theta_{i}, \xi\left(\theta_{-i}\right)\right)
\end{aligned}
$$

$$
\begin{aligned}
& \left.+\frac{1-F\left(\theta_{i}\right)}{f\left(\theta_{i}\right)} \lambda\left(Q_{i}\left(\theta_{i}\right)\right) C_{\theta_{i}}\left(Q_{i}\left(\theta_{i}\right), \theta_{i}, \xi\left(\theta_{-i}\right)\right)\right] \\
& \cdot p_{i}\left(\theta_{i}, \theta_{-\mathrm{i}}\right) \prod_{i=1}^{N} f\left(\theta_{i}\right) \mathrm{d} \theta_{1} \ldots \mathrm{d} \theta_{N} .
\end{aligned}
$$

Based on the assumptions and feasibility conditions it follows that

$$
\begin{aligned}
& \frac{\partial w\left(Q_{i}\left(\theta_{i}\right)\right)-C\left(Q_{i}\left(\theta_{i}\right), \theta_{i}, \xi\left(\theta_{-i}\right)\right)}{\partial \theta_{i}}>0, \\
& -\frac{\partial c_{v}\left(1-\lambda\left(Q_{i}\left(\theta_{i}\right)\right)\right) C\left(Q_{i}\left(\theta_{i}\right), \theta_{i}, \xi\left(\theta_{-i}\right)\right)}{\partial \theta_{i}} \\
= & c_{v} \lambda_{\theta_{i}}\left(Q_{i}\right) C\left(Q_{i}, \theta_{i}, \xi\right)-c_{v}\left(1-\lambda\left(Q_{i}\right)\right) C_{\theta_{i}}\left(Q_{i}, \theta_{i}, \xi\right)>0, \\
& \frac{\partial \frac{1-F\left(\theta_{i}\right)}{f\left(\theta_{i}\right)} \lambda\left(Q_{i}\left(\theta_{i}\right)\right) C_{\theta_{i}}\left(Q_{i}\left(\theta_{i}\right), \theta_{i}, \xi\left(\theta_{-i}\right)\right)}{\partial \theta_{i}} \\
= & \frac{\mathrm{d} \frac{1-F\left(\theta_{i}\right)}{f\left(\theta_{i}\right)}}{\mathrm{d} \theta_{i}} \lambda\left(Q_{i}\right) C_{\theta_{i}}\left(Q_{i}, \theta_{i}, \xi\left(\theta_{-i}\right)\right) \\
& +\frac{1-F\left(\theta_{i}\right)}{f\left(\theta_{i}\right)}\left(\lambda_{\theta_{i}}\left(Q_{i}\right) C_{\theta_{i}}\left(Q_{i}, \theta_{i}, \xi\left(\theta_{-i}\right)\right)\right) \\
& +\lambda\left(Q_{i}\right) C_{\theta_{i} \theta_{i}}\left(Q_{i}, \theta_{i}, \xi\left(\theta_{-i}\right)\right)>0,
\end{aligned}
$$$$
\frac{\partial\left[w\left(Q_{i}\left(\theta_{i}\right)\right)-C\left(Q_{i}\left(\theta_{i}\right), \theta_{i}, \xi\left(\theta_{-i}\right)\right)-c_{v}\left(1-\lambda\left(Q_{i}\left(\theta_{i}\right)\right)\right) C\left(Q_{i}\left(\theta_{i}\right), \theta_{i}, \xi\left(\theta_{-i}\right)\right)+\frac{1-F\left(\theta_{i}\right)}{f\left(\theta_{i}\right)} \lambda\left(Q_{i}\left(\theta_{i}\right)\right) C_{\theta_{i}}\left(Q_{i}\left(\theta_{i}\right), \theta_{i}, \xi\left(\theta_{-i}\right)\right)\right]}{\partial \theta_{i}}>0 .
$$

To summarize, in the optimal direct mechanism the public sector's expected revenue $W\left(Q_{i}\left(\theta_{i}\right), T_{i}\left(\theta_{i}\right)\right)$ increases with $\theta_{i}$. Moreover, the condition for maximizing the public sector's expected revenue Eq. (25) is $\theta_{i}=\max _{j \in N} \theta_{j}$, where $p_{i}\left(\theta_{i}, \theta_{-i}\right)=1$ and the optimal quality submitted by private sector $i$ satisfies the following:

$$
\begin{aligned}
Q_{i}^{*}\left(\theta_{i}\right)= & \operatorname{argmax}\left[w\left(Q_{i}\left(\theta_{i}\right)\right)-C\left(Q_{i}\left(\theta_{i}\right), \theta_{i}, \xi\left(\theta_{-i}\right)\right)\right. \\
& -c_{v}\left(1-\lambda\left(Q_{i}\left(\theta_{i}\right)\right)\right) C\left(Q_{i}\left(\theta_{i}\right), \theta_{i}, \xi\left(\theta_{-i}\right)\right) \\
& \left.+\frac{1-F\left(\theta_{i}\right)}{f\left(\theta_{i}\right)} \lambda\left(Q_{i}\left(\theta_{i}\right)\right) C_{\theta_{i}}\left(Q_{i}\left(\theta_{i}\right), \theta_{i}, \xi\left(\theta_{-i}\right)\right)\right] .
\end{aligned}
$$

Therefore, the optimal selection rule is

$$
p_{i}^{*}\left(\theta_{i}, \theta_{-i}\right)= \begin{cases}1 & \theta_{i}=\max \left\{\theta_{j}\right\}, \forall j \in N \\ 0 & \theta_{i} \neq \max \left\{\theta_{j}\right\}, \forall j \in N\end{cases}
$$

In other words, the private sector with the best integrated management capacity wins the bid.

Because of the single-crossing property, the hypotheses ensure that local incentive compatibility is equivalent to global incentive compatibility. The assumptions and feasibility conditions ensure that the second-order condition of $V\left(\tilde{\theta}_{i}, \theta\right)$ for announcements $\tilde{\theta}_{i}$ is satisfied. Therefore, $T_{i}^{*}\left(\theta_{i}\right)$ in the optimal direct mechanism is as follows:

$$
\begin{gathered}
\theta_{i}=\max \left\{\theta_{j}\right\}, \forall j \in N, \\
u^{*}\left(T_{i}^{*}\left(\theta_{i}\right)\right)=\frac{1}{F^{N-1}\left(\theta_{i}\right)}\left[U_{i}^{*}\left(\theta_{i}\right)+E_{\theta_{-i}} \lambda\left(Q_{i}^{*}\left(\theta_{i}\right)\right)\right.
\end{gathered}
$$




$$
\begin{aligned}
& \left.\cdot C\left(Q_{i}^{*}\left(\theta_{i}\right), \theta_{i}, \xi\left(\theta_{-i}\right)\right)\right] \\
= & \frac{1}{F^{N-1}\left(\theta_{i}\right)}\left[U_{i}^{*}(\underline{\theta})-E_{\theta_{-i}} \int_{\underline{\theta}}^{\theta_{i}} \lambda\left(Q_{i}(x)\right)\right. \\
\cdot & C_{\theta_{i}}\left(Q_{i}(x), x, \xi\left(\theta_{-i}\right)\right) p_{i}^{*}\left(\theta_{i}, \theta_{-i}\right) \mathrm{d} x \\
+ & \left.E_{\theta_{-i}} \lambda\left(Q_{i}^{*}\left(\theta_{i}\right)\right) C\left(Q_{i}^{*}\left(\theta_{i}\right), \theta_{i}, \xi\left(\theta_{-i}\right)\right)\right] \\
= & \frac{E_{\theta_{-i}}}{F^{N-1}\left(\theta_{i}\right)}\left[\lambda\left(Q_{i}^{*}\left(\theta_{i}\right)\right) C\left(Q_{i}^{*}\left(\theta_{i}\right), \theta_{i}, \xi\left(\theta_{-i}\right)\right)\right. \\
& \left.-\int_{\underline{\theta}}^{\theta_{i}} \lambda\left(Q_{i}^{*}(x)\right) C_{\theta_{i}}\left(Q_{i}^{*}(x), x, \xi\left(\theta_{-i}\right)\right) \mathrm{d} x\right] .
\end{aligned}
$$

So $T_{i}^{*}\left(\theta_{i}\right)=u^{*^{-1}}\left(T_{i}^{*}\left(\theta_{i}\right)\right)$ which is the inverse function of $u^{*}\left(T_{i}^{*}\left(\theta_{i}\right)\right)$.

Under the assumption that the public and private sectors are all risk neutral with respect to revenue, if private sector $i$ wins the bid in the optimal direct mechanism, the formula form for optimal generalized quality $Q_{i}^{*}\left(\theta_{i}\right)$ is equal to $Q_{i}^{*}\left(\theta_{i}\right)$. This is derived from the complete information reverse auction, minus $-\frac{1-F\left(\theta_{i}\right)}{f\left(\theta_{i}\right)} \lambda\left(Q_{i}\left(\theta_{i}\right)\right) C_{\theta_{i}}\left(Q_{i}\left(\theta_{i}\right), \theta_{i}\right.$, $\left.\xi\left(\theta_{-i}\right)\right)$, where $Q_{i}^{\prime *}\left(\theta_{i}\right)=\operatorname{argmax}\left[w\left(Q_{i}\left(\theta_{i}\right)\right)-C\left(Q_{i}\left(\theta_{i}\right)\right.\right.$, $\left.\left.\theta_{i}, \xi\left(\theta_{-i}\right)\right)-c_{v}\left(1-\lambda\left(Q_{i}\left(\theta_{i}\right)\right)\right) C\left(Q_{i}\left(\theta_{i}\right), \theta_{i}, \xi\left(\theta_{-i}\right)\right)\right]$, which maximizes social welfare function under perfect informa- tion. From an economic perspective, $-\frac{1-F\left(\theta_{i}\right)}{f\left(\theta_{i}\right)} \lambda\left(Q_{i}\left(\theta_{i}\right)\right)$ - $C_{\theta_{i}}\left(Q_{i}\left(\theta_{i}\right), \theta_{i}, \xi\left(\theta_{-i}\right)\right)$ can be construed as the information cost, provided by public sector to incentivize private sectors 'telling the truth' and eliminating the negative externality caused by information asymmetry. Che (1993)'s interpretation is that in a direct optimal mechanism, $Q_{i}^{*}\left(\theta_{i}\right)$ is distorted downward to limit the information cost accruing to relatively capable private sectors, while competition further curtails the absolute magnitude of the information cost. Thus, formula Eq. (26) inside the square brackets can be interpreted as the social welfare function under incomplete information which is equivalent to one under complete information minus information cost.

Thus, through Proposition 2, this paper draws the conclusion that, while the tenderer maximizes its selfprofit, it can realize the maximization of the social welfare under incomplete information as well, i.e., this mechanism not only ensures the bidder with highest integrated management capability will win the reverse auction but also realizes the maximization of the tenderer's revenue and the social welfare.

Corollary 1: In the optimal direct mechanism of a PPP project reverse auction, the optimal generalized quality $Q_{i}^{*}\left(\theta_{i}\right)$ is suboptimal.

Proof:

Under the condition of complete information, from the standpoint of maximizing social benefit, the best generalized quality $Q_{i}^{\prime *}\left(\theta_{i}\right)$ should be satisfied:

$$
\begin{aligned}
& \left.\frac{\partial W^{c}}{\partial Q_{i}}\right|_{Q_{i}=Q_{i}^{\prime *}\left(\theta_{i}\right)}=\left.\frac{\partial\left[w\left(Q_{i}\left(\theta_{i}\right)\right)-C\left(Q_{i}\left(\theta_{i}\right), \theta_{i}, \xi\left(\theta_{-i}\right)\right)-c_{v}\left(1-\lambda\left(Q_{i}\left(\theta_{i}\right)\right)\right) C\left(Q_{i}\left(\theta_{i}\right), \theta_{i}, \xi\left(\theta_{-i}\right)\right)\right]}{\partial Q_{i}}\right|_{Q_{i}=Q_{i}^{\prime *}\left(\theta_{i}\right)}=0 \\
& \left.\frac{\partial W^{c}}{\partial Q_{i}}\right|_{Q_{i}=Q_{i}^{\prime *}\left(\theta_{i}\right)}=w_{Q_{i}}\left(Q_{i}^{\prime *}\right)-C_{Q_{i}}\left(Q_{i}^{\prime *}, \theta_{i}, \xi\right)+c_{v} \lambda_{Q_{i}}\left(Q_{i}^{\prime *}\right) C\left(Q_{i}^{\prime *}, \theta_{i}, \xi\right)-c_{v}\left(1-\lambda\left(Q_{i}^{\prime *}\right)\right) C_{Q_{i}}\left(Q_{i}^{\prime *}, \theta_{i}, \xi\right)=0 .
\end{aligned}
$$

In the optimal direct mechanism of a PPP project reverse auction, the optimal generalized quality $Q_{i}^{*}\left(\theta_{i}\right)$ is satisfied

$$
\begin{aligned}
&\left.\frac{\partial W^{S}}{\partial Q_{i}}\right|_{Q_{i}=Q_{i}^{*}\left(\theta_{i}\right)}=0, \text { where } \\
& W^{S}= w\left(Q_{i}\left(\theta_{i}\right)\right)-C\left(Q_{i}\left(\theta_{i}\right), \theta_{i}, \xi\left(\theta_{-i}\right)\right)-c_{v}\left(1-\lambda\left(Q_{i}\left(\theta_{i}\right)\right)\right) \\
& \cdot C\left(Q_{i}\left(\theta_{i}\right), \theta_{i}, \xi\left(\theta_{-i}\right)\right)+\frac{1-F\left(\theta_{i}\right)}{f\left(\theta_{i}\right)} \lambda\left(Q_{i}\left(\theta_{i}\right)\right) \\
& \cdot C_{\theta_{i}}\left(Q_{i}\left(\theta_{i}\right), \theta_{i}, \xi\left(\theta_{-i}\right)\right)
\end{aligned}
$$$$
\left.\frac{\partial W^{S}}{\partial Q_{i}}\right|_{Q_{i}=Q_{i}^{*}\left(\theta_{i}\right)}=w_{Q_{i}}\left(Q_{i}^{*}\right)-C_{Q_{i}}\left(Q_{i}^{*}, \theta_{i}, \xi\right)
$$$$
+c_{v} \lambda_{Q_{i}}\left(Q_{i}^{*}\right) C\left(Q_{i}^{*}, \theta_{i}, \xi\right)
$$$$
-c_{v}\left(1-\lambda\left(Q_{i}^{*}\right)\right) C_{Q_{i}}\left(Q_{i}^{*}, \theta_{i}, \xi\right)
$$

$$
\begin{aligned}
& +\frac{1-F\left(\theta_{i}\right)}{f\left(\theta_{i}\right)}\left[\lambda_{Q_{i}}\left(Q_{i}^{*}\right) C_{\theta_{i}}\left(Q_{i}^{*}, \theta_{i}, \xi\right)\right. \\
& \left.+\lambda\left(Q_{i}^{*}\right) C_{\theta_{i} Q_{i}}\left(Q_{i}^{*}, \theta_{i}, \xi\right)\right]=0 .
\end{aligned}
$$

Based on Assumptions 2 and 5, $\lambda_{Q_{i}}\left(Q_{i}^{*}\right) C_{\theta_{i}}\left(Q_{i}^{*}, \theta_{i}, \xi\right)$ and $\lambda\left(Q_{i}^{*}\right) C_{\theta_{i} Q_{i}}\left(Q_{i}^{*}, \theta_{i}, \xi\right)$ are negative; therefore,

$$
\begin{aligned}
& w_{Q_{i}}\left(Q_{i}^{*}\right)-C_{Q_{i}}\left(Q_{i}^{*}, \theta_{i}, \xi\right)+\mathrm{c}_{v} \lambda_{Q_{i}}\left(Q_{i}^{*}\right) C\left(Q_{i}^{*}, \theta_{i}, \xi\right) \\
& -\mathrm{c}_{v}\left(1-\lambda\left(Q_{i}^{*}\right)\right) C_{Q_{i}}\left(Q_{i}^{*}, \theta_{i}, \xi\right) \\
= & -\frac{1-F\left(\theta_{i}\right)}{f\left(\theta_{i}\right)}\left[\lambda_{Q_{i}}\left(Q_{i}^{*}\right) C_{\theta_{i}}\left(Q_{i}^{*}, \theta_{i}, \xi\right)\right. \\
& \left.+\lambda\left(Q_{i}^{*}\right) C_{\theta_{i} Q_{i}}\left(Q_{i}^{*}, \theta_{i}, \xi\right)\right]>0
\end{aligned}
$$




$$
\begin{aligned}
= & w_{Q_{i}}\left(Q_{i}^{\prime *}\right)-C_{Q_{i}}\left(Q_{i}^{\prime *}, \theta_{i}, \xi\right) \\
& +\mathrm{c}_{v} \lambda_{Q_{i}}\left(Q_{i}^{\prime *}\right) C\left(Q_{i}^{\prime *}, \theta_{i}, \xi\right) \\
& -\mathrm{c}_{v}\left(1-\lambda\left(Q_{i}^{\prime *}\right)\right) C_{Q_{i}}\left(Q_{i}^{\prime *}, \theta_{i}, \xi\right) .
\end{aligned}
$$

From the assumptions and feasibility conditions, this paper can successively conclude that the social benefit under the complete information $W^{c}$ is concave in $Q_{i}$ that is

$$
w_{Q_{i} Q_{i}}-\left(1+c_{v}-c_{v} \lambda\right) C_{Q_{i} Q_{i}}+c_{v} \lambda_{Q_{i} Q_{i}} C+2 c_{v} \lambda_{Q_{i}} C_{Q_{i}}<0 .
$$

Thus, $Q_{i}^{\prime *}\left(\theta_{i}\right)$ is superior to $Q_{i}^{*}\left(\theta_{i}\right), Q_{i}^{*}\left(\theta_{i}\right)>Q_{i}^{*}\left(\theta_{i}\right)$ and in the optimal direct mechanism of a PPP project reverse auction, the optimal generalized quality is suboptimal.

Corollary 2: In the optimal direct mechanism of a PPP project reverse auction, the public sector should set an appropriate minimum quality level $Q_{0}$ according to the actual situation of the PPP project. Too high a minimum quality level $Q_{0}$ may reduce its revenue.

Proof:

In a direct mechanism of a PPP project reverse auction designed by the public sector, all private sectors will reveal their private information. Under the premise of maximizing its profit, the public sector wants to choose the private sector with the highest integrated management to win the bid by means of such a direct mechanism. This question can be described as follow:

$$
\begin{gathered}
\theta_{i}=\max _{j \in N} \theta_{j}, \\
W^{*}=\max _{i \in N} W^{*}\left(\theta_{i}\right)=\max _{i \in N} E_{\theta}\left[w\left(Q_{i}^{*}\left(\theta_{i}\right)\right)\right. \\
-\left(1+c_{v}\right)\left(1-\lambda\left(Q_{i}^{*}\left(\theta_{i}\right)\right)\right) C\left(Q_{i}^{*}\left(\theta_{i}\right), \theta_{i}, \xi\left(\theta_{-i}\right)\right)
\end{gathered}
$$

$$
\frac{\partial w_{Q_{i}}\left(Q_{i}^{*}\right)+c_{v} \lambda_{Q_{i}}\left(Q_{i}^{*}\right) C\left(Q_{i}^{*}, \theta_{i}, \xi\right)-C_{Q_{i}}\left(Q_{i}^{*}, \theta_{i}, \xi\right)-\left(1-\lambda\left(Q_{i}^{*}\right)\right) c_{\nu} C_{Q_{i}}\left(Q_{i}^{*}, \theta_{i}, \xi\right)}{\partial Q_{i}}<0 .
$$

From the foregoing, it's determined that the public sector should not set the minimum generalized quality level $Q_{0}$ too high. Let $Q^{*}$ be an economical quality. If the minimum generalized quality level is set too high, i.e., $Q_{0}>Q^{*}$, the PPP project benefits and efficiency will be reduced. In this case no one may participate in the reverse auction of PPP project. Therefore, the public sector should set the minimum generalized quality scientifically based on the construction conditions of the PPP project, the target market and the project goals, and should not unrealistically pursue superior quality. The PPP project should be matched to generalized quality, target, efficiency and profit.

Corollary 3: The optimal direct mechanism of the PPP project reverse auction can help the public sector reduce

$$
\left.-\mu\left(T_{i}^{*}\left(\theta_{i}\right)\right)\right] P_{i}\left(\theta_{i}, \theta_{-i}\right) .
$$

Combining Eqs. (33) and (34) is equivalent to $\frac{\partial W\left(\theta_{i}\right)}{\partial \theta_{i}}>0$

$$
\begin{aligned}
\frac{\partial W^{*}\left(\theta_{i}\right)}{\partial \theta_{i}}= & E_{\theta}\left[w_{\theta_{i}}\left(Q_{i}^{*}\right)+c_{v} \lambda_{\theta_{i}}\left(Q_{i}^{*}\right) C\left(Q_{i}^{*}, \theta_{i}, \xi\right)\right. \\
& -\left(1+c_{v}\right)\left(1-\lambda\left(Q_{i}^{*}\right)\right) C_{\theta_{i}}\left(Q_{i}^{*}, \theta_{i}, \xi\right) \\
& \left.-\mu_{\theta_{i}}\left(T_{i}^{*}\right)\right] P_{i}^{*}\left(\theta_{i}, \theta_{-i}\right) .
\end{aligned}
$$

Using Eq. (17) in Eq. (35), Eq. (36) can be derived:

$$
\begin{aligned}
\frac{\partial W^{*}\left(\theta_{i}\right)}{\partial \theta_{i}}= & E_{\theta}\left[w_{\theta_{i}}\left(Q_{i}^{*}\right)+c_{v} \lambda_{\theta_{i}}\left(Q_{i}^{*}\right) C\left(Q_{i}^{*}, \theta_{i}, \xi\right)\right. \\
& -\left(1+c_{v}\right)\left(1-\lambda\left(Q_{i}^{*}\right)\right) C_{\theta_{i}}\left(Q_{i}^{*}, \theta_{i}, \xi\right)-\lambda_{\theta_{i}}\left(Q_{i}^{*}\right) \\
& \left.\cdot C\left(Q_{i}^{*}, \theta_{i}, \xi\right)-\lambda\left(Q_{i}^{*}\right) C_{\theta_{i}}\left(Q_{i}^{*}, \theta_{i}, \xi\right)\right] P_{i}^{*}\left(\theta_{i}, \theta_{-i}\right) \\
= & E_{\theta}\left[w_{Q_{i}}\left(Q_{i}^{*}\right)+c_{v} \lambda_{Q_{i}}\left(Q_{i}^{*}\right) C\left(Q_{i}^{*}, \theta_{i}, \xi\right)\right. \\
& \left.-C_{Q_{i}}\left(Q_{i}^{*}, \theta_{i}, \xi\right)-\left(1-\lambda\left(Q_{i}^{*}\right)\right) c_{v} C_{Q_{i}}\left(Q_{i}^{*}, \theta_{i}, \xi\right)\right] \\
& \cdot \frac{\mathrm{d} Q_{i}}{\mathrm{~d} \theta_{i}} P_{i}^{*}\left(\theta_{i}, \theta_{-i}\right)>0 .
\end{aligned}
$$

Because of $\frac{\mathrm{d} Q_{i}^{*}\left(\theta_{i}\right)}{\mathrm{d} \theta_{i}}>0$, Eq. (36) is equivalent to

$$
\begin{gathered}
\quad\left[w_{Q_{i}}\left(Q_{i}^{*}\right)+c_{v} \lambda_{Q_{i}}\left(Q_{i}^{*}\right) C\left(Q_{i}^{*}, \theta_{i}, \xi\right)-C_{Q_{i}}\left(Q_{i}^{*}, \theta_{i}, \xi\right)\right. \\
\left.-\left(1-\lambda\left(Q_{i}^{*}\right)\right) c_{v} C_{Q_{i}}\left(Q_{i}^{*}, \theta_{i}, \xi\right)\right]\left.\right|_{Q_{i}=Q_{0}}>0 .
\end{gathered}
$$

According to the assumptions and Eq. (24) we obtain investment and financial pressure.

Proof:

The investment of the public sector is $\left(1+c_{v}\right)$ $\cdot\left(1-\lambda\left(Q_{i}\left(\theta_{i}\right)\right)\right) C\left(Q_{i}\left(\theta_{i}\right), \theta_{i}, \xi\left(\theta_{-i}\right)\right)$. According to the assumptions and Eq. (18), the investment is decreasing in $\theta_{i}$ clearly, that is

$$
\begin{aligned}
& \frac{\partial\left(1+\mathrm{c}_{v}\right)\left(1-\lambda\left(Q_{i}\right)\right) C\left(Q_{i}, \theta_{i}, \xi\right)}{\partial \theta_{i}} \\
= & -\left(1+\mathrm{c}_{v}\right) \frac{\partial \lambda\left(Q_{i}\right)}{\partial Q_{i}} \frac{\partial Q_{i}}{\partial \theta_{i}} C\left(Q_{i}, \theta_{i}, \xi\right)+\left(1+\mathrm{c}_{v}\right) \\
& \cdot\left(1-\lambda\left(Q_{i}\right)\right) \frac{\partial C\left(Q_{i}, \theta_{i}, \xi\right)}{\partial \theta_{i}}>0 .
\end{aligned}
$$


3.5 Optimal multidimensional reverse auction of a PPP project

A superior mechanism design must have a Nash equilibrium, and be implemented. Thus, in this section, this paper studies optimal multidimensional reverse auction schemes which achieve the optimal allocation $\left(Q_{i}^{*}\left(\theta_{i}\right), T_{i}^{*}\left(\theta_{i}\right)\right)$ defined in Proposition 2. According to Che (1993)'s research, the core problem with designing a multidimensional reverse auction is in formulating an appropriate scoring function which helps the public sector evaluate the tender schemes and select the successful tenderer. A spontaneous idea for the scoring function is the public sector's expected revenue. However, this scoring function can only ensure that all private sectors will provide the best generalized quality $Q_{i}^{\prime *}\left(\theta_{i}\right)$ which is optimal under complete information. However, it cannot stimulate them to provide optimal allocation under incomplete information. Therefore, it is necessary to adjust the scoring function or improve the reverse auction procedure. This section will discuss two feasible multidimensional reverse auctions of a PPP project, one adjusting the scoring function in a first-score reverse auction, the other establishing a special two-stage firstscore reverse auction (Branco, 1997).

\subsubsection{Function adjustment in a first-score reverse auction}

Let $S\left(Q_{i}\left(\theta_{i}\right), T_{i}\left(\theta_{i}\right)\right)$ denote the scoring function for private sector $i$ 's bidding document, $\left(Q_{i}\left(\theta_{i}\right), T_{i}\left(\theta_{i}\right)\right)$. The scoring rule is published in the bidding document; therefore, it is common knowledge. The scoring function is as follow:

$$
\begin{aligned}
\text { When } Q_{i}\left(\theta_{i}\right) \in[ & \left.Q^{*}(\underline{\theta}), Q^{*}(\bar{\theta})\right], \\
S\left(Q_{i}\left(\theta_{i}\right), T_{i}\left(\theta_{i}\right)\right)= & w\left(Q_{i}\left(\theta_{i}\right)\right)-\left(1+c_{v}\right) \\
& \cdot\left(1-\lambda\left(Q_{i}\left(\theta_{i}\right)\right)\right) C\left(Q_{i}\left(\theta_{i}\right), \theta_{i}, \xi\left(\theta_{-i}\right)\right) \\
& -\mu\left(T_{i}\left(\theta_{i}\right)\right)+\int_{Q_{i}^{*}(\theta)}^{Q_{i}} \frac{1-F\left(Q_{i}^{*-1}(x)\right)}{f\left(Q_{i}^{*-1}(x)\right)} \\
& \cdot\left[\lambda_{Q_{i}}(x) C_{\theta_{i}}\left(x, Q_{i}^{*-1}(x), \xi\left(\theta_{-i}\right)\right)\right. \\
& \left.+\lambda(x) C_{\theta_{i} Q_{i}}\left(x, Q_{i}^{*-1}(x), \xi\left(\theta_{-i}\right)\right)\right] \mathrm{d} x . \quad(40)
\end{aligned}
$$

When $Q_{i}\left(\theta_{i}\right) \notin\left[Q^{*}(\underline{\theta}), Q^{*}(\bar{\theta})\right]$,

$$
S\left(Q_{i}\left(\theta_{i}\right), T_{i}\left(\theta_{i}\right)\right)=-\infty .
$$

Proposition 3: Under such a scoring function $S\left(Q_{i}\right.$ $\left.\left(\theta_{i}\right), T_{i}\left(\theta_{i}\right)\right)$, the first-score reverse auction implements the optimal direct mechanism, and the optimal allocation $\left(Q_{i}^{*}\left(\theta_{i}\right), T_{i}^{*}\left(\theta_{i}\right)\right)$ in Proposition 2 can be achieved.

Proof:
The core idea behind proving Proposition 3 is whether the equilibrium solution under such a scoring rule is equivalent to the optimal allocation $\left(Q_{i}^{*}\left(\theta_{i}\right), T_{i}^{*}\left(\theta_{i}\right)\right)$ in Proposition 2. During the reverse auction process of document preparation, private sectors pursue not only the maximal profit but also maximizing the score, that is

$$
\begin{aligned}
& \max \left[U_{i}\left(\theta_{i}\right)+S\left(Q_{i}\left(\theta_{i}\right), T_{i}\left(\theta_{i}\right)\right)\right] \\
= & w\left(Q_{i}\left(\theta_{i}\right)\right)-C\left(Q_{i}\left(\theta_{i}\right), \theta_{i}, \xi\left(\theta_{-i}\right)\right) \\
& -c_{v}\left(1-\lambda\left(Q_{i}\left(\theta_{i}\right)\right)\right) C\left(Q_{i}\left(\theta_{i}\right), \theta_{i}, \xi\left(\theta_{-i}\right)\right) \\
& +\int_{Q_{i}^{*}(\theta)}^{Q_{i}} \frac{1-F\left(Q_{i}^{*-1}(x)\right)}{f\left(Q_{i}^{*-1}(x)\right)} \\
& \cdot\left[\lambda_{Q_{i}}(x) C_{\theta_{i}}\left(x, Q_{i}^{*-1}(x), \xi\left(\theta_{-i}\right)\right)\right. \\
& \left.+\lambda(x) C_{\theta_{i} Q_{i}}\left(x, Q_{i}^{*-1}(x), \xi\left(\theta_{-i}\right)\right)\right] \mathrm{d} x,
\end{aligned}
$$

where $Q_{i}\left(\theta_{i}\right) \notin\left[Q^{*}(\underline{\theta}), Q^{*}(\bar{\theta})\right], \quad S\left(Q_{i}\left(\theta_{i}\right), T_{i}\left(\theta_{i}\right)\right)=-\infty$; therefore, this paper does not discuss this condition. When $Q_{i}\left(\theta_{i}\right) \in\left[Q^{*}(\underline{\theta}), Q^{*}(\bar{\theta})\right]$, we take the derivative of Eq. (42) with respect to $Q_{i}$.

$$
\begin{aligned}
& \frac{\partial\left[U_{i}+S\left(Q_{i}, T_{i}\right)\right]}{\partial Q_{i}} \\
= & w_{Q_{i}}\left(Q_{i}\left(\theta_{i}\right)\right)-C_{Q_{i}}\left(Q_{i}\left(\theta_{i}\right), \theta_{i}, \xi\left(\theta_{-i}\right)\right) \\
& -c_{v}\left(1-\lambda\left(Q_{i}\left(\theta_{i}\right)\right)\right) C_{Q_{i}}\left(Q_{i}\left(\theta_{i}\right), \theta_{i}, \xi\left(\theta_{-i}\right)\right) \\
& +c_{v} \lambda_{Q_{i}}\left(Q_{i}\left(\theta_{i}\right)\right) C\left(Q_{i}\left(\theta_{i}\right), \theta_{i}, \xi\left(\theta_{-i}\right)\right) \\
& \left.+\frac{1-F\left(Q_{i}^{*-1}\left(Q_{i}\left(\theta_{i}\right)\right)\right)}{f\left(Q_{i}^{*}-1\right.}\left(Q_{i}\left(\theta_{i}\right)\right)\right) \\
& \cdot\left[\lambda_{Q_{i}}\left(Q_{i}\left(\theta_{i}\right)\right) C_{\theta_{i}}\left(Q_{i}\left(\theta_{i}\right), Q_{i}^{*-1}\left(Q_{i}\left(\theta_{i}\right)\right), \xi\left(\theta_{-i}\right)\right)\right. \\
+ & \left.\lambda\left(Q_{i}\left(\theta_{i}\right)\right) C_{\theta_{i} Q_{i}}\left(Q_{i}\left(\theta_{i}\right), Q_{i}^{*-1}\left(Q_{i}\left(\theta_{i}\right)\right), \xi\left(\theta_{-i}\right)\right)\right]=0 .
\end{aligned}
$$

According to Proposition 2, when $Q_{i}\left(\theta_{i}\right)=Q_{i}^{*}\left(\theta_{i}\right)$, the first-order condition Eq. (43) is satisfied. In addition, according to the assumptions and feasibility conditions the second-order condition of Eq. (42) in $Q_{i}$ can also be ensured. Thus, under such a scoring function $S\left(Q_{i}\left(\theta_{i}\right), T_{i}\left(\theta_{i}\right)\right)$, i.e., the generalized quality submitted by private sectors is optimal. Similarly, $T_{i}\left(\theta_{i}\right)=T_{i}^{*}\left(\theta_{i}\right)$ can be determined.

According to Proposition 3, to implement the optimal scoring rule, the public sector can not only induce the 
private sectors to disclose their own integrated management capacity but also incentivize them to provide the optimal generalized quality in the bidding document under incomplete information. The optimal scoring rule can effectively improve the allocation of social resources and social welfare.

\subsubsection{Two-stage first-score reverse auction}

In this subsection, this paper will establish a special twostage first-score reverse auction to implement the optimal direct mechanism. The reverse auction procedure is as follows: In the first stage, the private sector bids on the PPP project. The successful bidder will be the one whose score is highest. In the next stage, the public sector will bargain with the successful bidder to determine the level of generalized quality. Let $\tilde{S}\left(Q_{i}\left(\theta_{i}\right), T_{i}\left(\theta_{i}\right)\right)$ denote the scoring function for private sector $i$ 's bidding document in first stage.

$$
\begin{aligned}
\tilde{S}_{i}= & \tilde{S}\left(\theta_{i}\right)=\tilde{S}\left(Q_{i}\left(\theta_{i}\right), T_{i}\left(\theta_{i}\right)\right) \\
= & w\left(Q_{i}\left(\theta_{i}\right)\right)-\left(1+c_{v}\right) \\
& \cdot\left(1-\lambda\left(Q_{i}\left(\theta_{i}\right)\right)\right) C\left(Q_{i}\left(\theta_{i}\right), \theta_{i}, \xi\left(\theta_{-i}\right)\right)-\mu\left(T_{i}\left(\theta_{i}\right)\right) .
\end{aligned}
$$

To make the analysis simple, this paper makes the following assumptions, which are similar to those of Branco (1997).

Assumption 7: Through bargaining in the second stage, the optimal generalized quality will always be reached.

Assumption 8: The costs of the private sector $i$ are only correlated with $\theta_{-i(1)}$ which is the capability of the secondmost-capable private sector participant, denoted by $C\left(Q_{i}\left(\theta_{i}\right), \theta_{i}, \theta_{-i(1)}\right)$, where $\xi\left(\theta_{-i}\right)=\theta_{-i(1)}$.

Assumption 9: All private sectors except $i$ use the bidding function $\tilde{b}\left(\theta_{j}\right)=\left(\tilde{Q}\left(\theta_{j}\right), \tilde{T}\left(\theta_{j}\right)\right)$, which ensures that the associated score increases with the private sectors' capability $\theta_{j}$, and they do not 'tell a lie'.

Assumption 10 (boundary conditions): Let $\mu(T(\underline{\theta}))$ be equivalent to $C(Q(\underline{\theta}), \underline{\theta}, \xi(\underline{\theta}, \underline{\theta}, \ldots, \underline{\theta}))$.

The reason for Assumption 7 is that this paper focuses on implementing a mechanism, not the process of bargaining in the second stage. Assumption 9 guarantees that each score exists as an inverse function, denoted by $\Theta\left(\tilde{S}_{j}\right)$, which lets public sector obtain the actual level of integrated management capacity.

Proposition 4: This special two-stage first-score reverse auction implements the optimal direct mechanism.

Proof:

According to the assumptions, the optimal generalized quality $Q_{i}^{*}\left(\theta_{i}\right)$ will always be reached. Therefore, the core idea behind proving Proposition 4 is whether the concession period $T_{i}\left(\theta_{i}\right)$ in the symmetric equilibrium of such a reverse auction is equivalent to $T_{i}^{*}\left(\theta_{i}\right)$ in Proposition 2. Private sector $i$ will prepare the bidding documents to resolve the following question, where $\theta_{-i(1)} \leqslant \theta_{i}$.

$$
\begin{aligned}
U_{i}\left(\theta_{i}\right)= & \max _{Q_{i}, T_{i}} \int_{\underline{\theta}}^{\Theta\left(\tilde{S}_{i}\right)}\left[\mu\left(T_{i}\left(\theta_{i}\right)\right)-\lambda\left(Q_{i}\left(\theta_{i}\right)\right)\right. \\
& \left.\left.\cdot C\left(Q_{i}\left(\theta_{i}\right), \theta_{i}, \theta_{-i(1)}\right)\right)\right] f\left(\theta_{-i(1)}\right) \mathrm{d} \theta_{-i(1)} .
\end{aligned}
$$

Using Eq. (44), Eq. (45) can be rewritten as

$$
\begin{aligned}
U_{i}\left(\theta_{i}\right)= & \max _{Q_{i}, S_{i}} \int_{\underline{\theta}}^{\Theta\left(\tilde{S}_{i}\right)}\left[w\left(Q_{i}\left(\theta_{i}\right)\right)-C\left(Q_{i}\left(\theta_{i}\right), \theta_{i}, \theta_{-i(1)}\right)\right. \\
& \left.-c_{v}\left(1-\lambda\left(Q_{i}\left(\theta_{i}\right)\right) C\left(Q_{i}\left(\theta_{i}\right), \theta_{i}, \theta_{-i(1)}\right)\right)-\tilde{S}_{i}\right] \\
& \cdot f\left(\theta_{-i(1)}\right) \mathrm{d} \theta_{-i(1)} .
\end{aligned}
$$

Because of the feasibility conditions and assumptions, the first-order conditions of Eq. (46) are

$$
\begin{aligned}
& \frac{\mathrm{d} w\left(Q_{i}\left(\theta_{i}\right)\right)}{\mathrm{d} Q_{i}} F\left(\theta_{i}\right)-\int_{\underline{\theta}}^{\theta_{i}}\left[\frac{\partial C\left(Q_{i}\left(\theta_{i}\right), \theta_{i}, \theta_{-i(1)}\right)}{\partial Q_{i}}\right. \\
& -\frac{\mathrm{d} \lambda\left(Q_{i}\left(\theta_{i}\right)\right)}{\mathrm{d} Q_{i}} c_{v} C\left(Q_{i}\left(\theta_{i}\right), \theta_{i}, \theta_{-i(1)}\right) \\
& +\left(1-\lambda\left(Q_{i}\left(\theta_{i}\right)\right) c_{v} \frac{\partial C\left(Q_{i}\left(\theta_{i}\right), \theta_{i}, \theta_{-i(1)}\right)}{\partial Q_{i}}\right] \\
& \cdot f\left(\theta_{-i(1)}\right) \mathrm{d} \theta_{-i(1)}=0, \\
& F\left(\theta_{i}\right)+\left[w\left(Q_{i}\left(\theta_{i}\right)\right)-C\left(Q_{i}\left(\theta_{i}\right), \theta_{i}, \theta_{i}\right)\right. \\
& \left.-\mathrm{c}_{v}\left(1-\lambda\left(Q_{i}\left(\theta_{i}\right)\right) C\left(Q_{i}\left(\theta_{i}\right), \theta_{i}, \theta_{i}\right)\right)-\tilde{S}_{i}\right] \\
& \cdot f\left(\theta_{i}\right) \frac{\mathrm{d} \Theta\left(\tilde{S}\left(\theta_{i}\right)\right)}{\mathrm{d} \tilde{S}_{i}}=0,
\end{aligned}
$$

From the first-order condition the equality can be determined:

$$
\begin{aligned}
\frac{\mathrm{d} w\left(Q_{i}\left(\theta_{i}\right)\right)}{\mathrm{d} Q_{i}}= & E\left\{\frac{\partial C\left(Q_{i}\left(\theta_{i}\right), \theta_{i}, \theta_{-i(1)}\right)}{\partial Q_{i}}\right. \\
& \left.-\frac{\partial \lambda\left(Q_{i}\left(\theta_{i}\right) \mathrm{c}_{v} C\left(Q_{i}\left(\theta_{i}\right), \theta_{i}, \theta_{-i(1)}\right)\right.}{\partial Q_{i}} \mid \theta_{-i(1)}<\theta_{i}\right\},
\end{aligned}
$$




$$
\begin{aligned}
\frac{\mathrm{d} \tilde{S}\left(\theta_{i}\right)}{\mathrm{d} \theta_{i}}= & \frac{f\left(\theta_{i}\right)}{F\left(\theta_{i}\right)}\left[w\left(Q_{i}\left(\theta_{i}\right)\right)-C\left(Q_{i}\left(\theta_{i}\right), \theta_{i}, \theta_{i}\right)\right. \\
& \left.-\mathrm{c}_{v}\left(1-\lambda\left(Q_{i}\left(\theta_{i}\right)\right) C\left(Q_{i}\left(\theta_{i}\right), \theta_{i}, \theta_{i}\right)\right)-\tilde{S}_{i}\right] .
\end{aligned}
$$

Using Eq. (44) in Eq. (50), we determine:

$$
\begin{aligned}
& \frac{\mathrm{d} w\left(Q_{i}\left(\theta_{i}\right)\right)}{\mathrm{d} Q_{i}} \frac{\mathrm{d} Q_{i}\left(\theta_{i}\right)}{\mathrm{d} \theta_{i}}+\left(1+\mathrm{c}_{v}\right) \lambda_{\theta_{i}}\left(Q_{i}\left(\theta_{i}\right)\right) C\left(Q_{i}\left(\theta_{i}\right), \theta_{i}, \theta_{i}\right) \\
- & \left(1+\mathrm{c}_{v}\right)\left(1-\lambda\left(Q_{i}\left(\theta_{i}\right)\right)\right) C_{\theta_{i}}\left(Q_{i}\left(\theta_{i}\right), \theta_{i}, \theta_{i}\right) \\
& -\frac{\mathrm{d} \mu\left(T_{i}\left(\theta_{i}\right)\right)}{\mathrm{d} T_{i}} \frac{\mathrm{d} T_{i}\left(\theta_{i}\right)}{\mathrm{d} \theta_{i}} \\
= & \left.\frac{f\left(\theta_{i}\right)}{F\left(\theta_{i}\right)}\left[\mu\left(T_{i}\left(\theta_{i}\right)\right)-\lambda\left(Q_{i}\left(\theta_{i}\right)\right) C\left(Q_{i}\left(\theta_{i}\right), \theta_{i}, \theta_{i}\right)\right)\right], \\
& \frac{\mathrm{d} \mu\left(T_{i}\left(\theta_{i}\right)\right)}{\mathrm{d} T_{i}} \frac{\mathrm{d} T_{i}\left(\theta_{i}\right)}{\mathrm{d} \theta_{i}} \\
= & E\left\{\left(\frac{\partial C\left(Q_{i}\left(\theta_{i}\right), \theta_{i}, \theta_{-i(1)}\right)}{\partial Q_{i}}\right.\right. \\
& \left.\left.-\frac{\partial \lambda\left(Q_{i}\left(\theta_{i}\right) c_{v} C\left(Q_{i}\left(\theta_{i}\right), \theta_{i}, \theta_{-i(1)}\right)\right.}{\partial Q_{i}}\right) \frac{\mathrm{d} Q_{i}\left(\theta_{i}\right)}{\mathrm{d} \theta_{i}} \mid \theta_{-i(1)}<\theta_{i}\right\} \\
& -\left(1-\lambda\left(Q_{i}\left(\theta_{i}\right)\right)\right) C_{\theta_{i}}\left(Q_{i}\left(\theta_{i}\right), \theta_{i}, \theta_{i}\right) . \\
& \left.-\frac{f\left(\theta_{i}\right)}{F\left(\theta_{i}\right)}\left[\mu\left(T_{i}\left(\theta_{i}\right)\right)-\lambda\left(Q_{i}\left(\theta_{i}\right)\right) C\left(Q_{i}\left(\theta_{i}\right), \theta_{i}, \theta_{i}\right)\right)\right] \\
& \left(1+\mathrm{c}_{v}\right) \lambda_{\theta_{i}}\left(Q_{i}\left(\theta_{i}\right)\right) C\left(Q_{i}\left(\theta_{i}\right), \theta_{i}, \theta_{i}\right)+\left(1+\mathrm{c}_{v}\right)
\end{aligned}
$$

Because of the boundary condition, in symmetric equilibrium we find the unique solution:

$$
\begin{aligned}
\mu\left(T_{i}\left(\theta_{i}\right)\right)= & E\left\{\lambda\left(Q_{i}\left(\theta_{i}\right)\right) C\left(Q_{i}\left(\theta_{i}\right), \theta_{i}, \theta_{-i(1)}\right)\right. \\
& \left.-\int_{\underline{\theta}}^{\theta_{i}} \lambda\left(Q_{i}(x)\right) C_{\theta_{i}}\left(Q_{i}(x), x, \theta_{-i(1)}\right) \mathrm{d} x \mid \theta_{-i(1)}<\theta_{i}\right\} \\
= & \frac{1}{F^{N-1}\left(\theta_{i}\right)}\left\{E _ { \theta _ { - i } } \left[\lambda\left(Q_{i}\left(\theta_{i}\right)\right) C\left(Q_{i}\left(\theta_{i}\right), \theta_{i}, \xi\left(\theta_{-i}\right)\right)\right.\right. \\
& \left.\left.-\int_{\underline{\theta}}^{\theta_{i}} \lambda\left(Q_{i}(x)\right) C_{\theta_{i}}\left(Q_{i}(x), x, \xi\left(\theta_{-i}\right)\right) \mathrm{d} x\right]\right\} .
\end{aligned}
$$

By the inverse method, we find in this two-stage firstscore reverse auction the concession period $T_{i}\left(\theta_{i}\right)$ in symmetric equilibrium is equivalent to $T_{i}^{*}\left(\theta_{i}\right)$ in Proposition 2.

\section{Numerical example}

The government intends to construct a large infrastructure project adopting the PPP model. For convenience of the calculations, this paper assumes that there are four private sector participants in the reverse auction, and their capabilities are $0.8,0.85,0.9$ and 0.95 . The distribution function $\theta_{i}$ is uniformly distributed on the interval $[0,1]$, where $f\left(\theta_{i}\right)=1$ and $F\left(\theta_{i}\right)=\theta_{i}$. There is no welfare cost of raising public funds, that is $c_{v}=0$. The index of social efficiency and technology is constant, $\xi\left(\theta_{-i}\right)=1$.

According to the assumptions, the cost function is

$$
C\left(Q_{i}\left(\theta_{i}\right), \theta_{i}, \xi\left(\theta_{-i}\right)\right)=Q_{i}^{\frac{6}{5}}\left(4-\sqrt{\theta_{i}}\right),
$$

the investment weight function of the PPP project is

$$
\lambda\left(Q_{i}\left(\theta_{i}\right)\right)=Q_{i}^{\frac{4}{5}},
$$

and the entire value of fulfilling the PPP project is

$$
w\left(Q_{i}\left(\theta_{i}\right)\right)=8 \sqrt{Q_{i}} .
$$

In the optimal first-score reverse auction, the optimal function of generalized quality is

$$
Q_{i}^{*}=\left(\frac{8}{16-5 \theta_{i}^{\frac{1}{2}}+\theta_{i}^{-\frac{1}{2}}}\right)^{\frac{2}{3}}
$$

We assume the profit function is $\mu T_{i}\left(\theta_{i}\right)=\frac{1}{5} \sqrt{T_{i}}$, thus the function for the optimal concession period is

$$
T_{i}^{*}=25\left[\frac{1}{2} Q_{i}^{* 2}\left(4-\sqrt{\theta_{i}}\right)+\frac{1}{4 \theta_{i}^{3}} \int_{0}^{\theta_{i}} Q_{i}^{* 2} x^{\frac{5}{2}} \mathrm{~d} x\right]^{2} .
$$

We can calculate the data concerning quality, concession period, revenue of public sector and scoring under the optimal first-score reverse auction in a tabular format as shown below.

Table 2 shows that under scoring rule Eq. (40) of a firstscore reverse auction, the private sectors' bidding strategy, $\left(Q_{i}\left(\theta_{i}\right), T_{i}\left(\theta_{i}\right)\right)$ is equivalent to that of optimal allocation $\left(Q_{i}^{*}\left(\theta_{i}\right), T_{i}^{*}\left(\theta_{i}\right)\right)$, which is increasing in their capability $\theta_{i}$. Therefore, the feasibility condition of Proposition 1 has been proved. Second, the public sector can incentivize the private sector to report their own integrated management capacity truthfully using such a scoring rule, because their profit for 'telling the truth' is higher than when not telling 
Table 2 The results for a direct mechanism of a PPP project

\begin{tabular}{lcccccc}
\hline$\theta_{i}$ & $Q_{i}^{*}$ & $\lambda_{i}$ & $T_{i}^{*}$ & $\left(1-\lambda_{i}\right) C$ & $W$ & $s_{i}$ \\
\hline 0.80 & 0.736931 & 0.693286 & 19.2705 & 0.746132 & 5.14634 & 5.11461 \\
0.85 & 0.743651 & 0.700879 & 19.6924 & 0.726470 & 5.16019 & 5.12794 \\
0.90 & 0.750249 & 0.708348 & 20.1105 & 0.707159 & 5.17371 & 5.14117 \\
0.95 & 0.756742 & 0.715711 & 20.5257 & 0.688162 & 5.18693 & 5.15420 \\
\hline
\end{tabular}

the truth. For example, if the private sector participant's own capability is $\theta_{i}=0.9$, and if it mimics $\tilde{\theta}_{i}=0.95$ to win the reverse auction, its profit will be lower than that of telling the truth, $V\left(\tilde{\theta}_{i}, \theta_{i}\right)=0.0324248<0.038142=$ $V\left(\theta_{i}, \theta_{i}\right)$. Third, this scoring rule increases with the private sectors' capability, and can incentivize them to maximize social welfare and public sector revenue according to its own capabilities. Thus, the participant with the highest capability will win the reverse auction. Fourth, such a reverse auction of a PPP project can help the public sector reduce financial pressure, since the investment $\left(1-\lambda_{i}\right) C$ is decreasing with $\theta_{i}$. According to Table 2, the higher the integrated management capacity the winner possesses, the lower the cost the public sector needs to pay. In conclusion, the results of this illustrative example are consistent with the propositions of this paper. Therefore, it is feasible to implement the direct mechanism through the optimal multidimensional reverse auction of a PPP project.

\section{Concluding remarks}

In reverse auctions for the fulfillment of PPP projects, the public sector that organizes the infrastructure construction cares not only about its investment in carrying out the project and the concession period for operating the project but also about the generalized quality that will be provided. In such situations, the public sector often designs multidimensional reverse auctions involving investment structure, concession period and generalized quality.

Based on the characteristic of a PPP project reverse auction and the theory of group evaluation, this paper builds the summary function of generalized quality to reduce the dimensions of information and simplify discussions. Based on the theory of mechanism design and the revelation principle, this paper studies the twodimensional direct mechanism on the concession period and generalized quality, considers the influence of investment structure, and describes the feasibility conditions, equilibrium solution and generalized quality requirements of such a mechanism. In contrast to current research, this paper not only designed a one-stage first-score reverse auction, where the public sector adjusts the scoring function, which is similar to Che (1993)'s research, but also established a special two-stage first-score reverse auction. In this example, in the first stage, the public sector evaluates each bidding document based on the score function, and in the second stage, the public sector bargains with the selected private sector participant to maximize the ex-ante welfare, where the public sector may evaluate the level of generalized quality through its virtual social value. This paper shows that these two feasible multidimensional reverse auctions can implement the optimal mechanism, and the optimal allocation $\left(p_{i}^{*}\left(\theta_{i}\right.\right.$, $\left.\left.\theta_{-i}\right), Q_{i}^{*}\left(\theta_{i}\right), T_{i}^{*}\left(\theta_{i}\right)\right)$ can be achieved. Finally, numerical analysis was performed to prove the effectiveness and feasibility of the direct mechanism.

It is worth noting that this paper focuses on the direct mechanism of a PPP project reverse auction; therefore, the summary function of generalized quality is only a feasible theoretical method. The function index system needs to be established more systematically, and the method for index calculation lacks practicability. Therefore, how to establish the generalized quality index system of a PPP project and build the summary function scientifically and systematically is a direction of further research. Not only that, because of limit of many assumption, there still seems to be a gap between real cases and theoretical research, and the part about example is confined to numerical calculation, which is short of quality features of PPP project. Therefore, how to inextricably link theoretical research with real case is also the direction of further research.

Acknowledgements This research was supported by the National Natural Science Foundation of China (Grant Nos. 71231007 and 71373222).

\section{References}

Bichler M (2000). An experimental analysis of multi-attribute auctions. Decision Support Systems, 29(3): 249-268

Bichler M (2001). The Furture of E-Markets: Multi-Dimensional Market Mechanisms. Cambridge: Cambridge University Press

Branco F (1996). Multiple unit auctions of an indivisible good. Economic Theory, 8(1): 77-101

Branco F (1997). The design of multidimensional auctions. Rand Journal of Economics, 28(1): 63-81

Che I L (1993). Design competition through multidimensional auctions. Rand Journal of Economics, 24(4): 668-680

Che Y K, Kim J W (2009). Optimal collusion-proof auctions. Journal of Economic Theory, 144(2): 565-603

Chukwuemeka A, Amadi N N, Nyenke C U (2013). Public spending on transport infrastructure and economic growth in Nigeria. Journal of 
Sociological Research, 4(2): 438-446

David A S, Azoulay-Schwartz R, Kraus S (2006). Bidding in sealed-bid and English multi-attribute auctions. Decision Support Systems, 42 (2): $527-556$

Dequiedt V (2007). Efficient collusion in optimal auctions. Journal of Economic Theory, 136(1): 302-323

Dong F Y (2013). Study on the system of tender evaluation index in BOT construction project. Dissertation for the Doctoral Degree. Wuhan: Wuhan University of Technology (in Chinese)

Hanák T (2016). Electronic reverse auctions in public construction procurement-Empirical evidence from the Czech Republic. Archives of Civil Engineering, 62(3): 47-60

Hua A P (2014). Research on marketization of public affairs in city management-A case study of the market bidding of Wuxi sanitation. Thesis for the Master's Degree. Shanghai: East China University of Political Science and Law (in Chinese)

Huang H, Chen J (2010). Mechanism design on auctioning procurement contracts and bargainin. Journal of Management Sciences in China, 13(3): 1-7 (in Chinese)

Ke Y, Wang S Q, Chan A P C, Lam P T I (2010). Preferred risk allocation in China's public-private partnership (PPP) projects. International Journal of Project Management, 28(5): 482-492

Lengwiler Y, Wolfstetter E (2010). Auctions and corruption: An analysis of bid rigging by a corrupt auctioneer. Journal of Economic Dynamics and Control, 34(10): 1872-1892

Li L (2016). China's infrastructure PPP mode selection research from perspective of game theory. Thesis for the Master's Degree.Nanjing: Nanjing University (in Chinese)

Myerson R (1979). Incentive compatibility and the bargaining problem. Econometrica, 47(1): 61-73
Nishimura T (2015). Optimal design of scoring auction with multidimensional quality. Review of Economic Design, 19(2): 117-143

Settoon R P, Wyld D C (2003). The ski slope to prosperity: An analysis of the potential impact of reverse auctions in government procurement in five southeast Asian nations. Asia Pacific Journal of Marketing and Logistics, 15(3): 3-19

Wang C, Dargahi F, Bhuiyan M F H (2012). On the tradeoff between privacy and efficiency: A bidding mechanism for scheduling noncommercial services. Computers in Industry, 63(6): 610-618

Wang H, Chen H M, Yang J X (2010). Optimal mechanism and its implementation in multidimensional auctions. Journal of Management Sciences in China, 13(8): 1-14 (in Chinese)

Wu X L, Zhou J, Wang J N, Chen X G (2012). The effect of twodimensional tender contract design on investment and concession term for BOT projects. Journal of Industrial Engineering and Engineering Management, 3: 191-196 (in Chinese)

Xu N (2014). Research on critical success factors of PPP mode for quasioperational urban infrastructure. Thesis for the Master's Degree. Chongqing: Chongqing University (in Chinese)

Yin H, Wang X J (2006). Optimal auction mechanism for complements. Systems Engineering - Theory \& Practice, 26(9): 60-66 (in Chinese)

Yin H, Wang X J (2008). Optimal auction mechanism design for government procurement. Journal of Systems \& Management, 17(4): 365-370 (in Chinese)

Zhao D M, Wang Y Y (2012). Model and analysis of collusion between the auction agent and corruptive bidder in multi-dimensional auction. Mathematics in Practice and Theory, 42(8): 26-35 (in Chinese)

Zhou Y X, Wang X J, Liu H F (2011). The bidding mechanism of dedicated capital investment and operations in regional logistics center. Systems Engineering - Theory \& Practice, 31(8): 1429-1440 